\title{
WestVirginiaUniversity
}

THE RESEARCH REPOSITORY @ WVU

Graduate Theses, Dissertations, and Problem Reports

2017

\section{Modeling and Simulation of a Direct-Write Manufacturing Process}

John Cordonier

Follow this and additional works at: https://researchrepository.wvu.edu/etd

\section{Recommended Citation}

Cordonier, John, "Modeling and Simulation of a Direct-Write Manufacturing Process" (2017). Graduate Theses, Dissertations, and Problem Reports. 5397.

https://researchrepository.wvu.edu/etd/5397

This Thesis is protected by copyright and/or related rights. It has been brought to you by the The Research Repository @ WVU with permission from the rights-holder(s). You are free to use this Thesis in any way that is permitted by the copyright and related rights legislation that applies to your use. For other uses you must obtain permission from the rights-holder(s) directly, unless additional rights are indicated by a Creative Commons license in the record and/ or on the work itself. This Thesis has been accepted for inclusion in WVU Graduate Theses, Dissertations, and Problem Reports collection by an authorized administrator of The Research Repository @ WVU. For more information, please contact researchrepository@mail.wvu.edu. 


\title{
Modeling and Simulation of a Direct-Write Manufacturing Process
}

\author{
John Cordonier
}

Thesis submitted to the

Benjamin M. Statler College of Engineering and Mineral Resources at West Virginia University in partial fulfillment of the requirements

for the degree of

Master of Science

In

Chemical Engineering

Department of Chemical and Biomedical Engineering

Debangsu Bhattacharyya, Ph.D., Chair

Rakesh Gupta, Ph.D.

Konstantinos Sierros, Ph.D.

Morgantown, West Virginia

2017

Keywords: Additive Manufacturing, Modeling, Simulation, Control 


\begin{abstract}
Modeling and Simulation of a Direct-Write Manufacturing Process
\end{abstract}

John Cordonier

Additive manufacturing (AM) is of great interest since complex geometry with varying composition and functionalities can be developed for a multitude of applications based on desired performance criteria. However, consistency of the products must be ensured. Operating conditions can be used as degrees of freedom so that the desired dimensions, geometries, and composition can be tightly controlled. In this project, direct writing of an ink composed of a conductive material dispersed in a polymer medium is used to create conductive pathways for use in flexible electronic devices.

To develop an efficient controls system, the parameters that affect the printed fluid must first be understood. The pattern geometry and dimensions created by the direct writing method mainly depend on three main factors: the properties of the ink, the parameters used in the operation of the direct-writing machine, and the ink-substrate interaction. In this work, a detailed model of the direct-write process is developed in COMSOL. While this model provides detailed information and very high resolution, the model is computationally expensive and is not suitable for control applications. A simple model suitable for real time simulation is developed in MATLAB. The effect of different operating conditions is studied. A control strategy is developed for efficient regulation of the track dimensions. 


\section{Acknowledgement}

I would like to thank my advisor Dr. Debangsu Bhattacharyya for his expertise, patience, and steadfast assistance with this project. Without his help none of this would have been possible. I'd also like to thank my parents Andy and Nancy Cordonier for their encouragement and wisdom in pursuing this master's degree. Their support made this effort possible.

I would like to thank my officemates for offering their expertise when I asked for it and for making this work interesting and enjoyable. I would also like to thank Dr. Pankaj Saha for his assistance with the simulation work related to COMSOL and thanks is due to Dr. Kostas Sierros for allowing me the use of his lab and equipment.

Funding for this research was provided in part by the NASA West Virginia Space Grant Consortium. Additional thanks is due to the COMSOL technical support team, for putting up with my incessant questions. 


\section{TABLE OF CONTENTS}

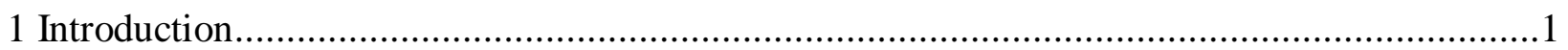

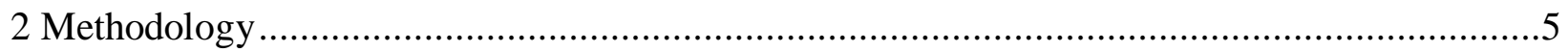

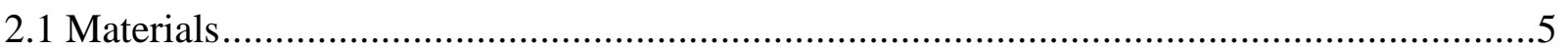

2.2 Ink Preparation ............................................................................................. 7

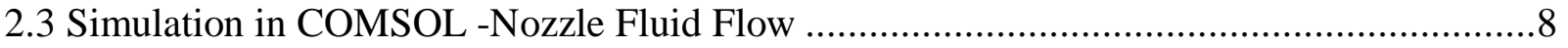

2.4 Simulation in MATLAB - Nozzle ...........................................................................

2.5 Simulation in COMSOL - Fluid track Deposition................................................. 11

2.6 Simulation in MATLAB - Fluid Track .................................................................. 13

2.7 Proportional Control - MATLAB ................................................................... 14

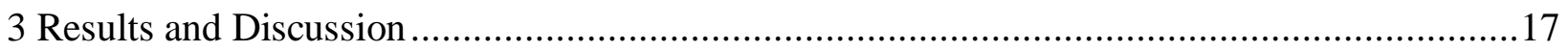

3.1 Model Validation - Ink Characterization............................................................. 17

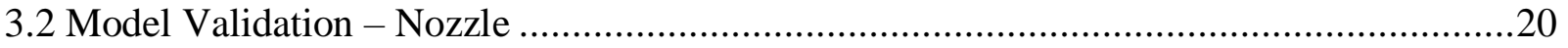

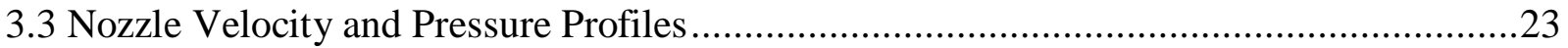

3.4 Model validation - Simulation in COMSOL ............................................................2 27

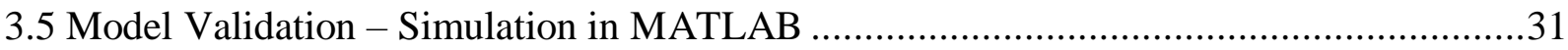

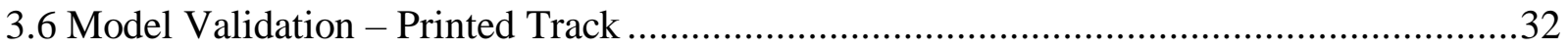

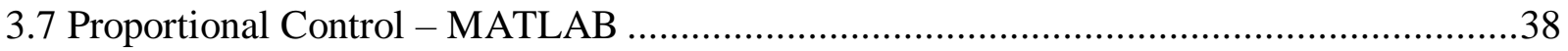

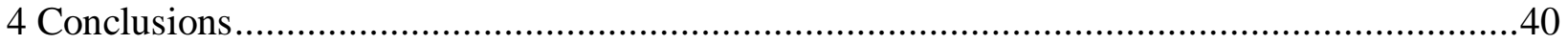

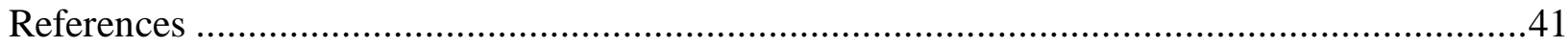

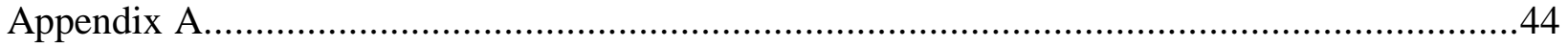




\section{LIST OF FIGURES}

Figure 1. Schematic of the direct write printing process .......................................................

Figure 2. The nozzle used in experiments preparing to print onto a glass substrate .....................6

Figure 3. Nordson 3-Axis Automated Dispensing System .................................................

Figure 4. Geometry of the nozzle used in the pressure and velocity profile studies. .....................8

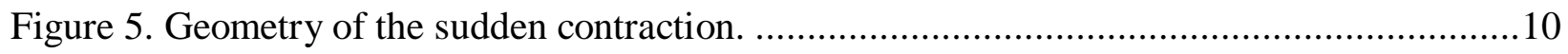

Figure 6. Geometry of the domain used in the track deposition studies....................................12

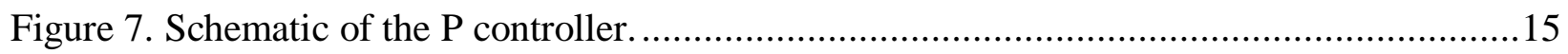

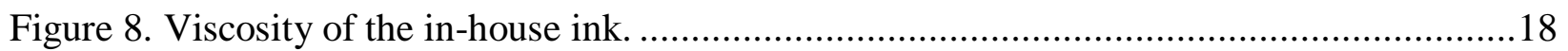

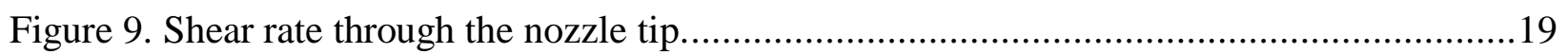

Figure 10. Newtonian versus non-Newtonian velocity profiles through the nozzle.....................20

Figure 11. The nozzle model and associated velocity magnitude using a) the actual dimensions

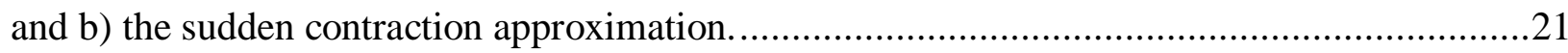

Figure 12. Comparison of the velocity profile at the tip of the nozzle between the actual dimensions of the nozzle and an approximation using a sudden contraction............................22

Figure 13. Velocity profiles through the nozzle as a function of tip radius..............................24

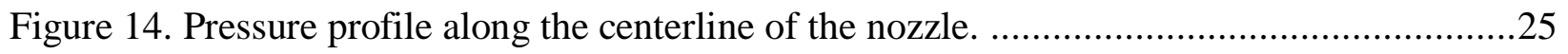

Figure 15. Velocity profile in the radial direction at axial position $9.1 \mathrm{~mm} . \ldots \ldots \ldots \ldots \ldots \ldots \ldots \ldots \ldots . . .26$

Figure 16. Pressure profile in the radial direction at axial position $9.1 \mathrm{~mm}$..............................26

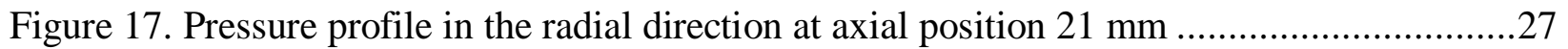

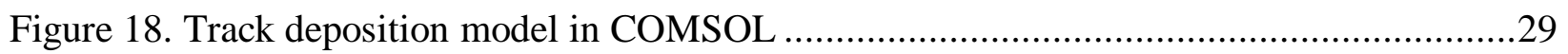

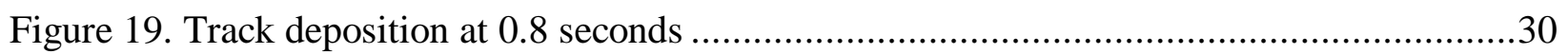

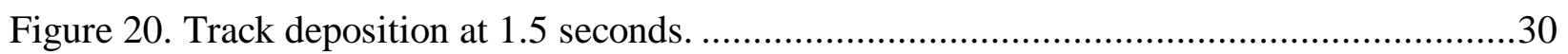

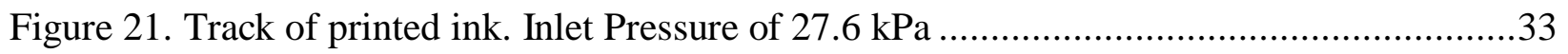

Figure 22. Track of printed ink. Inlet Pressure of $31.0 \mathrm{kPa}$....................................................

Figure 23. Track of printed ink. Inlet Pressure of $34.5 \mathrm{kPa}$....................................................

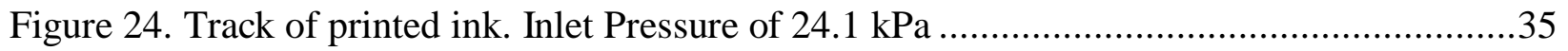

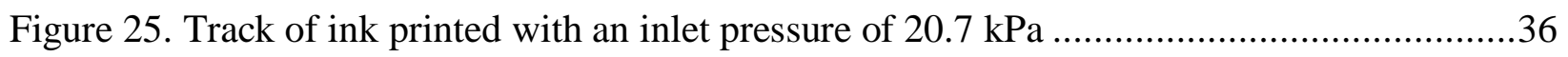

Figure 26. Change in track width for various inlet pressures...................................................

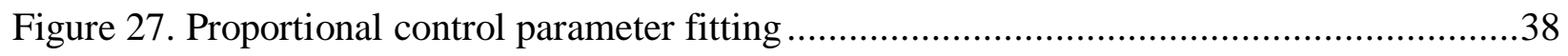

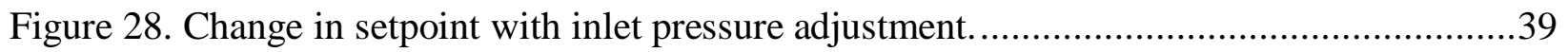

Figure 29. Dimensions of the domain for the COMSOL simulation ........................................4

Figure 30. Deposited track at the start of the deposition........................................................4 


\section{LIST OF TABLES}

Table 1. Pattern Morphology and Properties ............................................................................. 3

Table 2. Summary of the COMSOL model parameters ...................................................28

Table 3. Summary of the MATLAB model parameters.................................................. 31

Table 4. MATLAB model versus physical nozzle outlet comparison ..................................32

Table 5. MATLAB Model versus physical track width comparisons ....................................37 


\section{Introduction}

There is significant interest in additive manufacturing (AM). However, studies in the area of modeling, simulation, and control of AM processes are lacking. For instance, NASA's interest is clearly reflected by a thorough literature review titled "Additive Manufacturing Modeling and Simulation" published by the Langley Research Center in April of $2014^{1}$. The literature review shows lack of papers in the area of modeling and simulation of AM. In particular, there are only 12 papers cited on modeling of molten pool physics. Numerical models are very useful tools for evaluating the effect of operating parameters that can be manipulated during manufacturing to control the functionality of each layer ${ }^{2}$.

Similar lack of papers is observed in other AM technologies as well. For example, there has been a lack of thorough investigation into the numerical modeling of fluid track-deposition, and especially the breakup of the fluid, through the direct-write manufacturing process. Additionally, the breakup of liquid during deposition, specifically around the nozzle, has received little attention. Ubal et al. have taken the opportunity to analyze the steady state solution space in terms of the flow rate of the fluid and the nozzle-substrate standoff distance for a vertically pointing nozzle and a nozzle tilting at a slight angle ${ }^{3}$. All other parameters in their work are held constant. 
Direct writing (DW) signifies a group of sub- $\mu \mathrm{m}$ to $\mathrm{mm}$ scale additive manufacturing processes ${ }^{4}$ depositing, in plane or three-dimension (3D), functional materials called inks/pastes over substrates, following a preset pattern ${ }^{5}$. It employs a PC-controlled translation stage that moves relative to a device (eg. a dispensing nozzle) to pattern the ink. This setup is shown in Figure 1, adapted from Lewis and Gratson ${ }^{6}$.

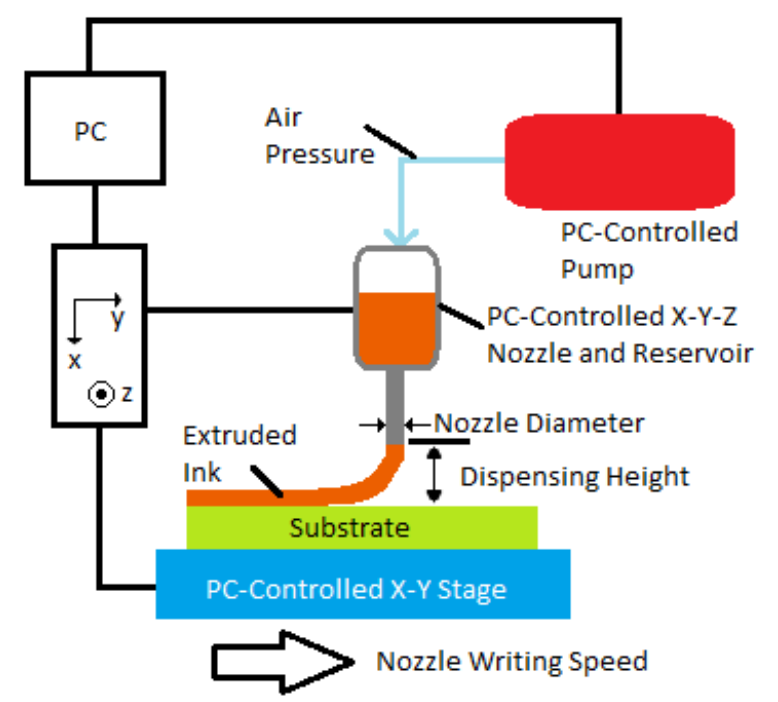

Figure 1. Schematic of the direct write printing process

The continuous flow direct writing process ${ }^{6,7}$, or robotic deposition, with a pneumatically operated nozzle for deposition of continuous ink filament is very promising for the fabrication of next generation energy components and devices. It has been introduced more than a decade ago ${ }^{8}$ and it has recently re-emerged due to its inherent ability to extrude a wide range of viscous materials ${ }^{9}$ thus enabling significant ink design freedom and fabrication of planar and 3D film/pattern architectures ${ }^{10}$ with varying resolution.

Robotic deposition has been used to pattern many nanoparticle colloidal suspension inks ${ }^{11,12}$ where complex interactions between suspension stability and its structural evolution are of great importance ${ }^{13,14,15}$. Nozzle tip geometry, shape, and size are important in forming the extrudate dimensions and shape ${ }^{16}$. Other parameters ${ }^{17}$ affecting the shape and dimensions of the 
final pattern include writing speed, extrusion pressure, and dispensing height. The versatility of the process is reflected on the numerous functional components/devices reported to date. They include varistors ${ }^{18}$, photonic crystals ${ }^{19}$, microfluidics ${ }^{20}$, conducting electrodes $^{21,22,23}$, antennas ${ }^{24}$, optical waveguides ${ }^{25}$, strain sensors ${ }^{26}$, touch pads ${ }^{27}$, and graphene scaffolds ${ }^{28,29}$. Recent examples of robotically deposited device prototypes include Li-ion microbatteries ${ }^{30}$ and light emitting diodes $^{31}$.

The additive manufacturing process known as direct writing involves the extrusion of a liquid polymer into a pre-determined geometry. Direct-write technologies allow the polymeric material to be printed freely in three dimensions. By using an ink composed of a conductive material, direct writing can be used to create conductive substrates or wiring for use in flexible electronic devices. However, there is a lack of literature on the control and optimization of nozzlebased robotic deposition (NBRD) of polymers for the creation of multi-functional substrates. The work presented in this paper aims to decrease that gap of knowledge.

The pattern morphology and properties created by the direct writing method are affected by three main factors: the properties of the ink, the parameters used in the operation of the direct writing machine, and the ink-substrate interaction ${ }^{32}$. These categories are further broken down in Table 1.

Table 1. Pattern Morphology and Properties

\begin{tabular}{|l|l|}
\hline \multirow{2}{*}{ Ink Properties } & Viscosity \\
\cline { 2 - 2 } & Surface tension \\
\hline \multirow{4}{*}{$\begin{array}{l}\text { Direct Writing } \\
\text { Parameters }\end{array}$} & Tip size \\
\cline { 2 - 2 } & Air pressure \\
\cline { 2 - 2 } & Writing speed \\
\cline { 2 - 2 } $\begin{array}{l}\text { Ink-Substrate } \\
\text { Interactions }\end{array}$ & Dispensing height \\
\cline { 2 - 2 } & Adhesion \\
\hline
\end{tabular}


COMSOL Multiphysics software is used in the analysis and comparison of these parameters $^{33}$. COMSOL allows the user to construct a unique geometry, in this case the inner dimensions of a nozzle provided by Nordson EFD ${ }^{\mathrm{TM}}$, and apply appropriate boundary conditions to attain the resultant solution. As stated earlier, the focus of this project is the analysis of the properties summarized in Table 1 to determine how changing parameters can affect the characteristics of the printed track the most. Specifically, the effect that inlet pressure has on the printed track width are investigated. Additionally, a parallel simulation is conducted in MATLAB for two primary reasons. One, a reduced model in MATLAB can be used for rapid estimation of the track width. Two, a validated reduced model can be used in controller development. The MATLAB simulation uses the same operating parameters with the exception that the fluid is treated simply as a Newtonian fluid rather than a non-Newtonian fluid, similar to the work by Ubal et $\mathrm{al}^{3}$. An analysis of the ink viscosity and its effect on the flow of the fluid in the nozzle is provided to validate this assumption.

For experimental purposes, an aqueous ink composed of titanium and poly(acrylic acid) (PAA) is used in the study of the deposition process. Briefly, this allows for low-energy, lowenergy deposition of inks useful in the manufacture of multi-functional materials ${ }^{34}$. 


\section{Methodology}

The work in this project consists primarily of data gathered by simulations in COMSOL and MATLAB. The simulation in MATLAB is split into two distinct parts: the simulation of the flow through the nozzle and the simulation of the deposited track of fluid. In COMSOL, the solution is obtained by creating a representative geometry and using the Phase Field method to track the interface between the fluid and the surrounding air. The meshing in COMSOL is completed automatically with a free-form triangular scheme. Instead of using a meshing for the MATLAB solution, the flow through the nozzle is solved algebraically and the deposited track is calculated using a set of differential algebraic equations. Since the Level Set Method solves both the Navier-Stokes equations in three dimensions and the continuity equation ${ }^{33}$ the simulation in COMSOL is intended as a "complete" simulation to validate the MATLAB model. A comparison of different MATLAB simulations to corresponding physical experiments is completed to further validate the MATLAB models. Additionally, a controls system has been developed in MATLAB so that the user of the NBRD technology will allow the user to print conductive inks with the characteristic width that they desire.

\subsection{Materials}

Chemicals used in this study were obtained from the manufacturers and processed without further purification. Poly(acrylic acid), titanium(IV) bis(ammonium lactato) dihydroxide solution, and titanium(IV) oxide nanopowder were obtained from Sigma-Aldrich. The poly(acrylic acid) obtained is suitable for use in synthesis of copolymers but is also soluble in water. The titanium(IV) bis(ammonium lactato) dihydroxide solution was obtained in a 50 wt.\% in $\mathrm{H}_{2} \mathrm{O}$ solution and was not altered before use in this study. The titanium(IV) oxide nanopowder had an average particle size of $21 \mathrm{~nm}$ and was also not altered before use. The carbon nanotubes were 
obtained from Bayer in the form of Baytubes C 150 P, an agglomerated powder commonly used as a polymeric additive for electrical conductivity and mechanical reinforcement.

Magnified images are taken with a Dino-Lite Edge digital microscope. A magnified image of a nozzle is shown in Figure 2. The distance between the nozzle and the substrate was kept constant throughout the experiments. This value was measured before each deposition took place.

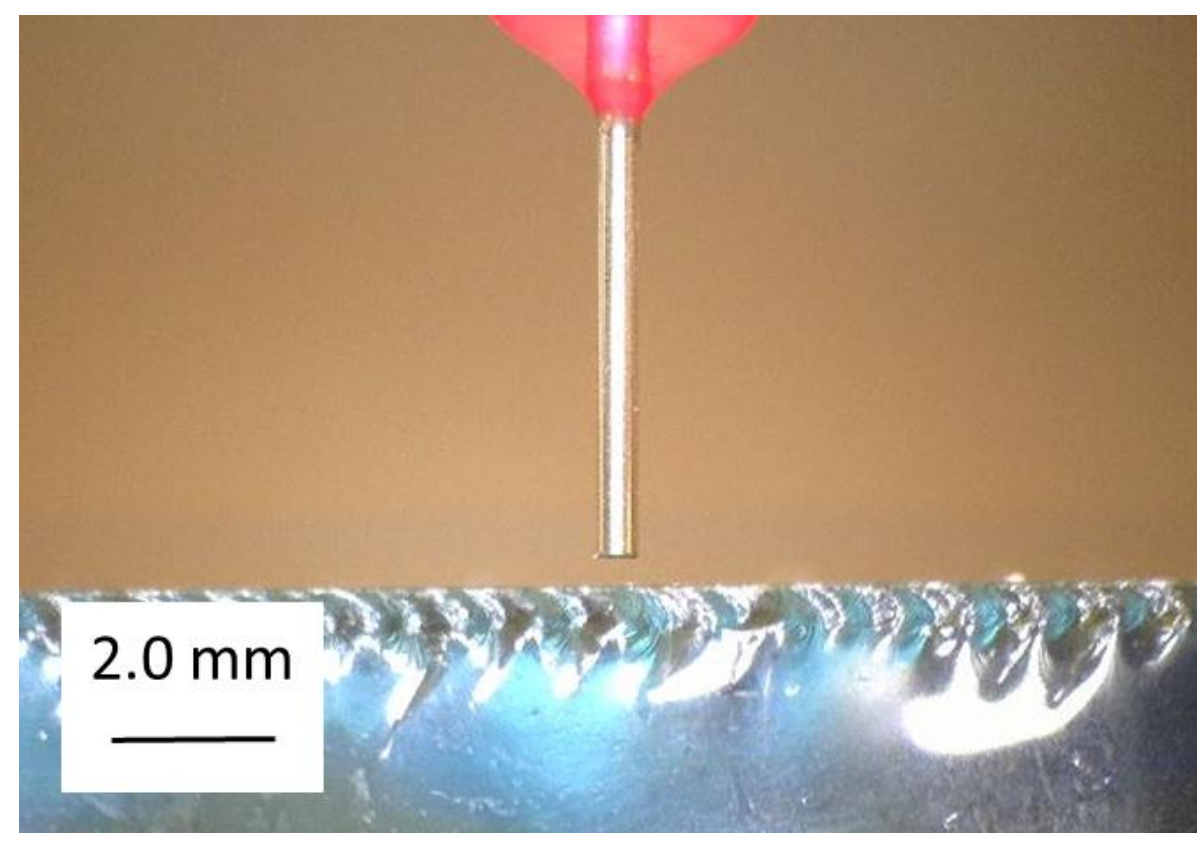

Figure 2. The nozzle used in experiments preparing to print onto a glass substrate The dispensing was carried out using a Nordson 3-Axis Automated Dispensing System, shown in Figure 3. The digital microscope is attached to the front of the printer stage. The nozzle used in every dispensing application is the 25 Gauge General Purpose Tip. The inner dimensions of the nozzle were determined from the 3D models of the nozzles available from Nordson. 


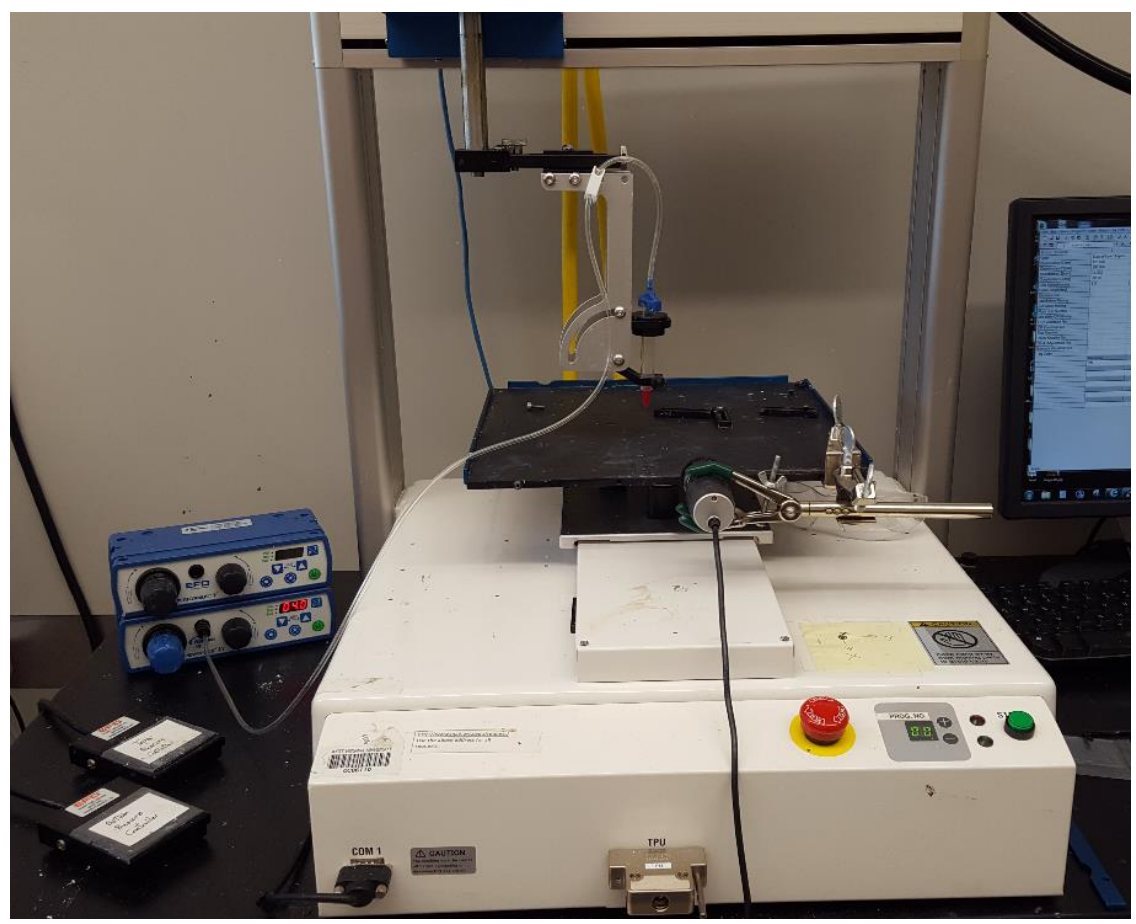

Figure 3. Nordson 3-Axis Automated Dispensing System

In order to operate this particular printer, first the desired nozzle path is identified using the software available with the printer. This identification includes a starting and ending point base on the 3-dimensional coordinate system, the path between those points, and parameters including the nozzle write speed. The user also specifies the desired inlet pressure using the pressure controller pictured left of the printer in Figure 3. Once the desired path is complete the user then sends this data to the printer and the printer completes a single pass of the identified route at the specified inlet pressure.

\subsection{Ink Preparation}

The ink used in this work was prepared similar to Arango et al. ${ }^{34}$ First, the polyacrylic acid (PAA) was mixed with DI water and left to stir for several hours until the solution appeared homogenous. The TALH solution was mixed with DI water and then subsequently mixed with the $\mathrm{TiO}_{2}$ particles. This solution was sonicated for 15 minutes and then mixed with a magnetic stir 
bar for an additional 15 minutes. After stirring, the PAA/DI water solution was added to the $\mathrm{TALH} / \mathrm{TiO}_{2}$ solution. The resultant solution was then, in order, stirred for 15 minutes, sonicated for 15 minutes, and stirred again for 1 hour. During each sonication, ice was added to the sonicator after 5 and 10 minutes to avoid a rise in bath-water temperature. All ink samples were stirred for approximately 10 minutes before being added to the syringes for deposition.

\subsection{Simulation in COMSOL -Nozzle Fluid Flow}

The inner dimensions of the nozzle used in this work were taken from the CAD files that Nordson EFD use for manufacturing. The geometry is split in half axially for use in an axisymmetric simulation. In the CFD module provided by COMSOL, the simulation has been completed for two main cases, both in singlephase flow - one for comparison with MATLAB and one for simulation of flow through the nozzle. In each case, both the continuity equation and the equation of motion are coupled to solve for the velocity and pressure profiles in the geometry. In this simulation software, the boundary conditions and fluid properties chosen by the user are automatically applied to obtain the resultant solution for each geometry.

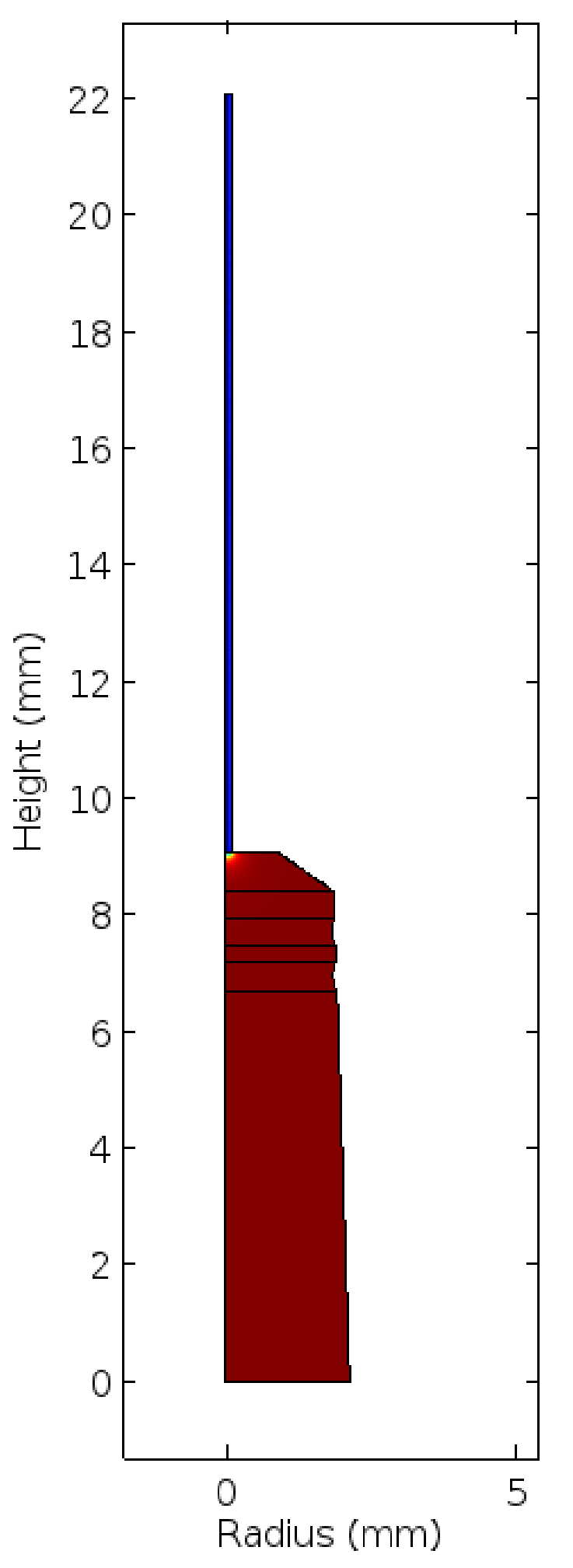

Figure 4. Geometry of the nozzle used in the pressure and velocity profile studies. 
The geometry of the nozzle is shown in Figure 4. The geometry of the nozzle is kept constant throughout the different simulations except for a change in the diameter of the tip of the nozzle, which begins a distance $9.1 \mathrm{~mm}$ from the bottom of the geometry. This area is highlighted in blue in Figure 4. All other variables, including inlet and outlet pressure, fluid viscosity and density, and boundary conditions are kept constant. Solutions from these simualtions are used to extract information on both the radial velocity profiles and the axial pressure profiles. Velocity profiles are compared against physical experiments, namely the average outlet velocity of the nozzle as determined from the mass flux.

\subsection{Simulation in MATLAB - Nozzle}

Similarly to COMSOL, the parallel simulation in MATLAB makes use of the equations of motion and continuity to solve for the velocity and pressure profiles in the given geometry. Part of the initial COMSOL simulation is validated for flow in the axial direction through a pipe. Assuming velocities in the $\mathrm{r}$ - and $\theta$-directions are zero and density remains unchanged, the equation of continuity is given by:

$$
\frac{\partial v_{z}}{\partial z}=0
$$

Applying Equation 1 results in the following simplification of the z-component of the Navier-Stokes equation for incompressible fluids in cylindrical coordinates:

$$
0=-\frac{\partial P}{\partial z}+\mu \frac{1}{r} \frac{\partial}{\partial r}\left(r \frac{\partial v_{z}}{\partial r}\right)
$$


where $\rho$ is the density, $\mu$ is the viscosity, and $P$ is the pressure. Since the solution for fluid flow through a pipe is well-documented, comparison of this solution with a solution obtained in COMSOL is completed.

For simplicity and fast solution, the nozzle is treated as a sudden contraction and is shown in blue in Figure 5.

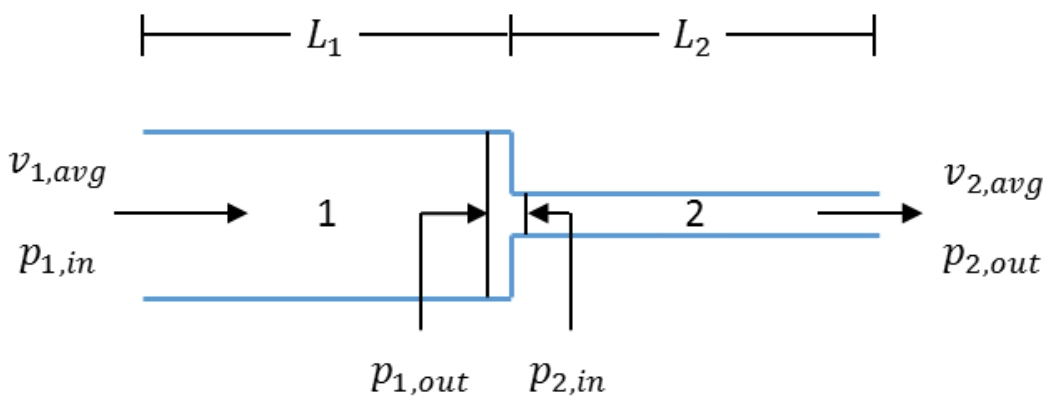

Figure 5. Geometry of the sudden contraction.

Since the flow in the simulations of interest are assumed to be laminar, the velocity profiles in Sections 1 and 2 can be described as parabolic. Using the Hagen-Poiseuille equation and the Bernoulli equation, the equations that describe the velocity and pressure through a sudden contraction are given by:

$$
\begin{aligned}
v_{1, \text { avg }} & =\frac{1}{2} \frac{\left(P_{1, \text { in }}-P_{1, \text { out }}\right) R_{1}^{2}}{4 \mu L_{1}} \\
P_{1, \text { out }}-P_{2, \text { in }} & =\frac{1}{2} \rho v_{2, \text { avg }}^{2}\left(1-\left(\frac{v_{1, \text { avg }}}{v_{2, \text { avg }}}\right)^{2}\right) \\
v_{2, \text { avg }} & =\frac{1}{2} \frac{\left(P_{2, \text { in }}-P_{\text {atm }}\right) R_{2}^{2}}{4 \mu L_{2}}
\end{aligned}
$$

where $v_{1, \text { avg }}$ is the average inlet velocity and $v_{2, \text { avg }}$ is the average outlet velocity. $P_{1, \text { in }}$ is the inlet pressure to the system, $P_{1, \text { out }}$ is the pressure just before the contraction, $P_{2, \text { in }}$ is the pressure following the contraction, and $P_{a t m}$ is the pressure at the outlet of the nozzle, which is 
assumed to be atmospheric. $\mu$ is the viscosity of the fluid, $\rho$ is the density of the fluid, and $L_{1}$ and $L_{2}$ are the lengths of Sections 1 and 2, respectively.

Inducing an inlet pressure and assuming atmospheric pressure at the outlet leaves four unknowns, namely the average velocity in each sections, pressure at the inlet of the contraction, and pressure at the outlet of the contraction. These variables can be solved for by using Equations 3, 4, and 5 and the mass balance between Sections 1 and 2. The outlet velocity $v_{2, a v g}$ can then be used in the fluid track model to calculate the width of the printed track.

\subsection{Simulation in COMSOL - Fluid track Deposition}

The simulation of the deposition process is completed in COMOSOL for the polymeric ink of interest. COMSOL solves the equations of continuity in three dimensions with a mass balance to calculate and track the deposition process. The purpose of the inclusion of the track deposition model in COMSOL is twofold. First, in essence it is a rigorous simulation used as a redundancy to verify the accuracy of the simulations in MATLAB. In this sense it is used specifically to validate the use of a sudden contraction approximation of the nozzle. Second, such an arduous simulation can be used as a "virtual experiment" whereby changes in operating parameters or fluid properties can be used to study the deposition of the ink without having to physically deposit the ink. Although the solution time for these simulations can be lengthy, they have the benefit of not requiring money being spent on lab equipment and materials and time being spent working in the lab.

The track deposition is completed using the Laminar Two-Phase Flow (TPF) Phase Field method available in the CFD module provided by COMSOL. The meshing used to solve the 
domain is created automatically in COMSOL using the available "physics-controlled mesh" option. Figure 6 shows the domain that is used to solve the track deposition.

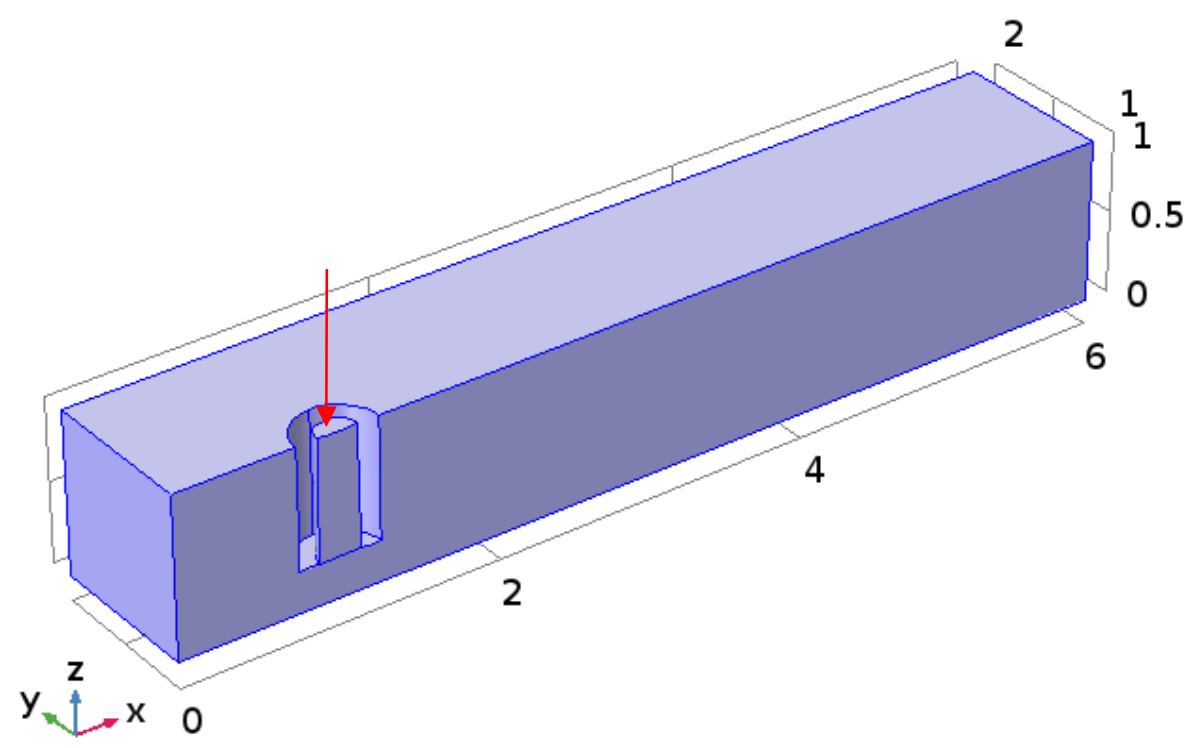

Figure 6. Geometry of the domain used in the track deposition studies.

The area shown in Figure 6 represents the tip of the nozzle, a substrate moving in the positive $\mathrm{x}$-direction, and the air surrounding the domain. All lengths are given in millimeters. The arrow indicates the inlet for the domain. A velocity profile is imposed at the inlet, the value of which corresponds to the appropriate mass flow rate for the corresponding inlet pressure. The cylindrical protrusion is representative of the tip of the nozzle filled with the fluid to be printed. The negative space around the nozzle inlet represents the wall of the nozzle and has a no-slip boundary condition on the inner and outer walls. The outlet to the domain is located at the plane $x=6$ and a pressure outlet of zero gauge pressure is applied. On the plane $y=0$ a symmetry boundary condition is used. This is done to decrease the solution time by solving only half of the domain. The solution is then mirrored across the symmetry axis. The remaining boundaries use 
an air inlet condition with inlet pressure set to zero gauge. This is done to prevent ink from accidentally entering the domain from anywhere except the specified inlet.

\subsection{Simulation in MATLAB - Fluid Track}

Simulation methods in MATLAB using reduced order modeling (ROM) methods for CFD applications can be complicated and time-consuming to be viable for control of a 3D printer. Some sources report solution times of under $20 \operatorname{seconds}^{35}$. This is unsuitable for applications in $3 \mathrm{D}$ printing since, depending on the size of the object, the printer may be able to print several layers in the span of 20 seconds. Similarly, others have explored ROM-generation techniques that result in the construction of models that require less than $1 \%$ of the time needed for a full CFD simulation $^{36}$. This results, unfortunately, in ROM solutions that may take on the order of minutes to complete.

Instead of using such the time-consuming ROM approach to modeling the deposition of a track of fluid, a model using a geometric approximation of the final track shape is developed. The change in the volume $\Delta V$ of fluid exiting the nozzle is directly related to the change in the shape of the deposited track as given by:

$$
\Delta V=\Delta l A_{c s}=\Delta l w^{2} a^{2}
$$

where 1 is the length of the track, $A_{c s}$ is the cross-sectional area of the track, w is the width of a track of fluid calculated by Ubal et al. ${ }^{3}$, and $a^{2}$ is a geometric parameter arising from the contact angle of the track with the substrate. $a^{2}$ is constant since the contact angle $\theta_{0}$ is constant and is given by:

$$
a^{2}=\frac{\theta_{0}-\sin \theta_{0} \cos \theta_{0}}{4 \sin ^{2} \theta_{0}}
$$


Rearranging Equation 6 to solve for width yields:

$$
w=\left(\frac{\Delta V}{\Delta l a^{2}}\right)^{1 / 2}
$$

Since what comes out of the nozzle gets deposited, mass conservation yields:

$$
A_{N} V_{2, a v g}-w^{2} a^{2} S=0
$$

where $A_{N}$ denotes the cross-sectional area of the nozzle and $\mathrm{S}$ denotes the writing speed where $\frac{d l}{d t}=S$

Several approximations are used in this derivation. The height and width of the track are based on the contact angle of the fluid assuming the track is semi-circular in shape and uniform. However, physical experiments of the ink deposition often results in uneven widths and heights of the track, usually due to unintended operating parameters (e.g. air bubble in the nozzle). Additionally, this model assumes that there is no loss of volume of the track due to evaporation of the solvent. Realistically, it can be expected that drying of the track will result in a decreased volume and cross-sectional area; however, that effect is not explored in this work.

\subsection{Proportional Control - MATLAB}

A proportional (P)-only controller is implemented in MATLAB using a digital approximation of the continuous analog proportional-integral-derivative (PID) controller. PID controllers have been successfully applied to various AM processes, including laser-based additive manufacturing ${ }^{37}$ and dropwise additive manufacturing of pharmaceutical products ${ }^{38}$, specifically on the heating elements involved in these processes. The schematic of this controller as applied 
to the DW process is given in Figure 7. Theoretically, either the writing speed of the nozzle or the inlet pressure to the system could be changed to achieve the desired track width.

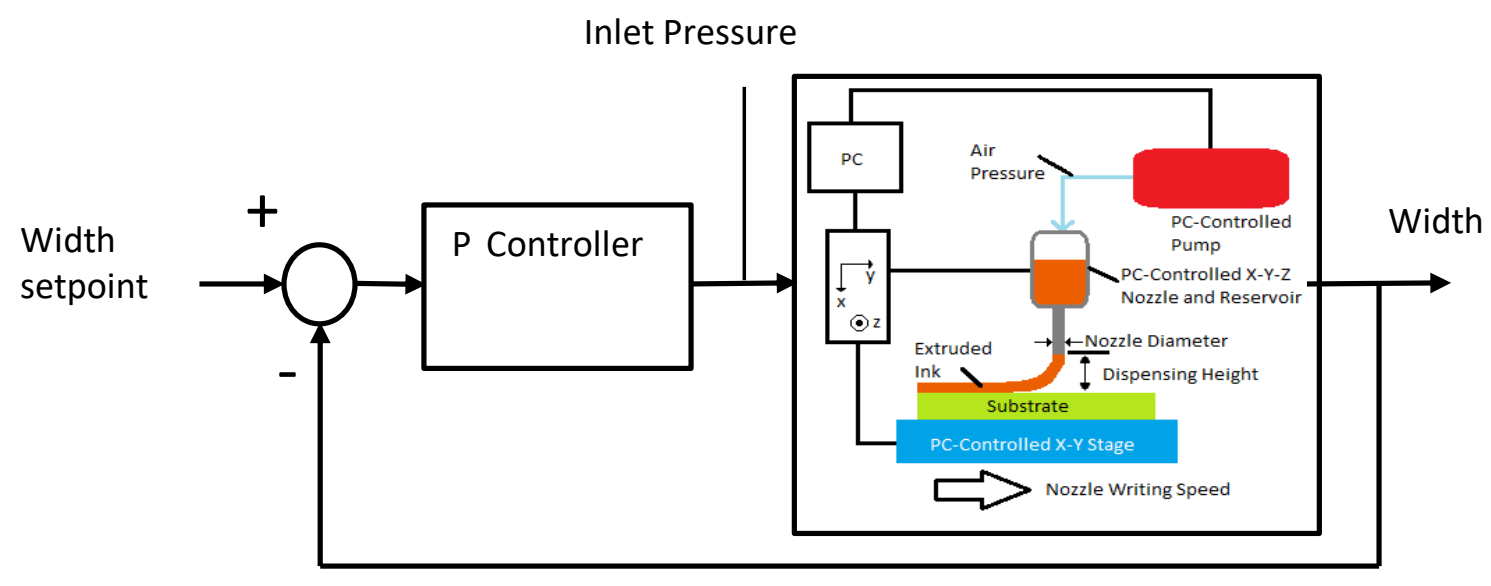

Figure 7. Schematic of the P controller.

The change in the width of the track is determined by the velocity form of the digital approximation. This equation is given $b^{39}$ :

$$
\Delta P_{\text {in }}(k)=K_{c}\left[\left(1+\frac{\Delta \mathrm{t}}{\tau_{I}}+\frac{\tau_{D}}{\Delta \mathrm{t}}\right) \varepsilon(k)-\left(\frac{2 \tau_{D}}{\Delta \mathrm{t}}+1\right) \varepsilon(k-1)+\frac{\tau_{D}}{\Delta \mathrm{t}} \varepsilon(k-2)\right]
$$

where $P_{i n}$ is the inlet pressure of the nozzle, $K_{C}$ is the gain of the system, $\mathrm{t}$ is the time, $\tau_{I}$ and $\tau_{D}$ are the integral and derivative time constants, respectively, and $\varepsilon(k)$ is given by:

$$
\varepsilon(k)=w(s p)-w(k)
$$

where $w(s p)$ is the track width setpoint and $w(k)$ is the track width at point $k$. Equation 10 represents the change in the "position" of the nozzle write speed. If the integral and derivative actions are neglected, Equation 10 reduces to:

$$
\Delta P_{i n}(k)=K_{c}[\varepsilon(k)]
$$


Equation 12 is the proportional controller response. This equation can be used to calculate the change in the nozzle write speed or inlet pressure necessary to achieve the desired track width. The parameter $K_{c}$ is determined by taking the inverse of the process gain, as given in Equation 13:

$$
K_{c}=\frac{1}{K_{p r}}
$$

,where $K_{p r}$ can be approximated as:

$$
K_{p r}=\frac{\Delta w}{\Delta P_{i n}}
$$

Comparing the width output to the pressure input allows for an estimation of the system gain $K_{p r}$. 


\section{Results and Discussion}

The results obtained from the various simulations can be broken down into several main categories. The initial comparison between the velocity profiles attained in COMSOL and MATLAB are used to verify the accuracy of the series of algebraic equations used to calculate the outlet velocity of the nozzle. Velocity and pressure profiles determined by COMSOL for the nozzle geometry shown in Figure 4 are shown for comparative purposes. A comparison between the MATLAB simulations and the physically printed tracks of ink are shown. Results of the simulated deposition in COMSOL are also shown. Results from the determination of the proportional control parameters are presented. This includes justification of the parameters by way of a comparison between differences in the expected track width and actual track width.

\subsection{Model Validation - Ink Characterization}

Use of the simulation programs is two-fold. First, the MATLAB model allows for rapid solution calculation and implementation in control schemes. Second, the CFD simulation, if accurate enough, can be used for design purposes to avoid time consuming and financially expensive experiments. Therefore it is necessary to compare the results of the simulations with physically printed tracks of ink. Although a summary of the ink characterization is given in the methodology, a more detailed examination is presented here

The behavior of the ink is very sensitive to its viscosity and the surface tension. Since the ink is polymer-based, the viscosity is dependent on the shear rate, as shown in Error! Reference source not found. At shear rates above $375 \mathrm{~s}^{-1}$, the viscometer's data is no longer accurate, so the data collection was stopped there. 


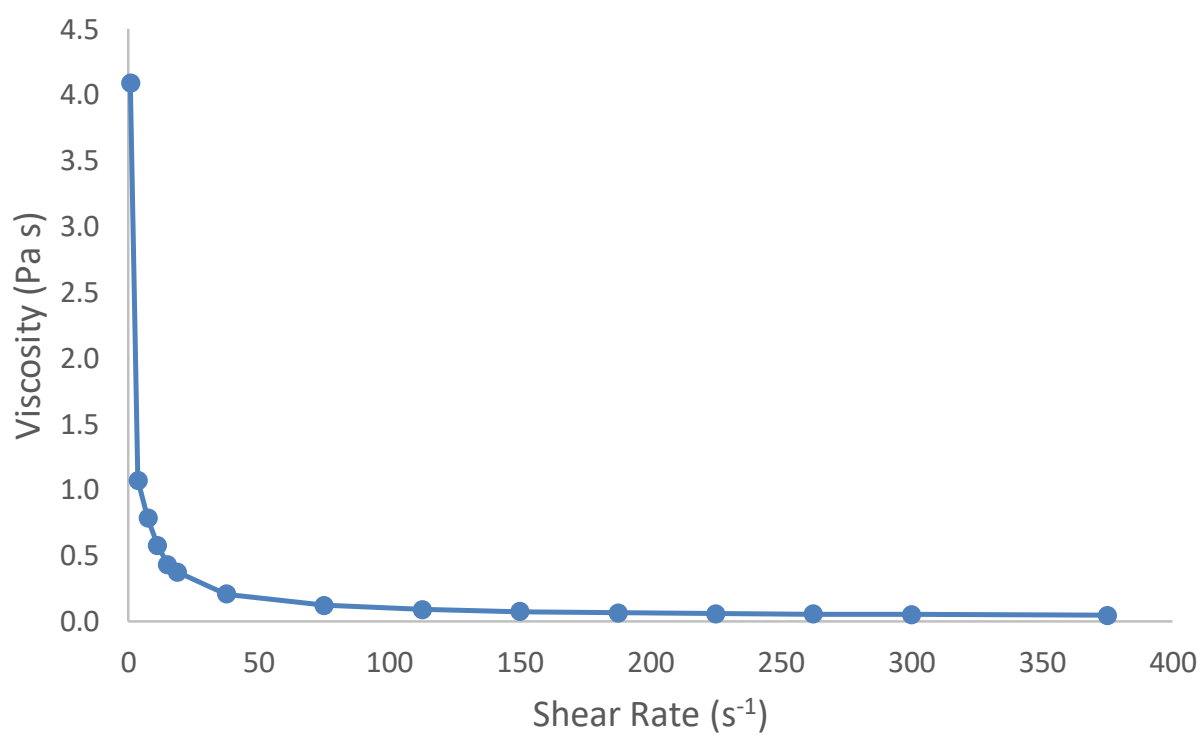

Figure 8. Viscosity of the in-house ink.

Therefore it is necessary to analyze the shear rate through the nozzle and specifically through the tip of the nozzle where the shear rate will be highest. COMSOL allows for the calculation of the shear rate, as shown in Figure 9. The results shown in Figure 9 are taken from simulations using an inlet pressure of $31.0 \mathrm{kPa}$. The shear rate analysis is completed by treating the fluid as a non-Newtonian power-law fluid. 


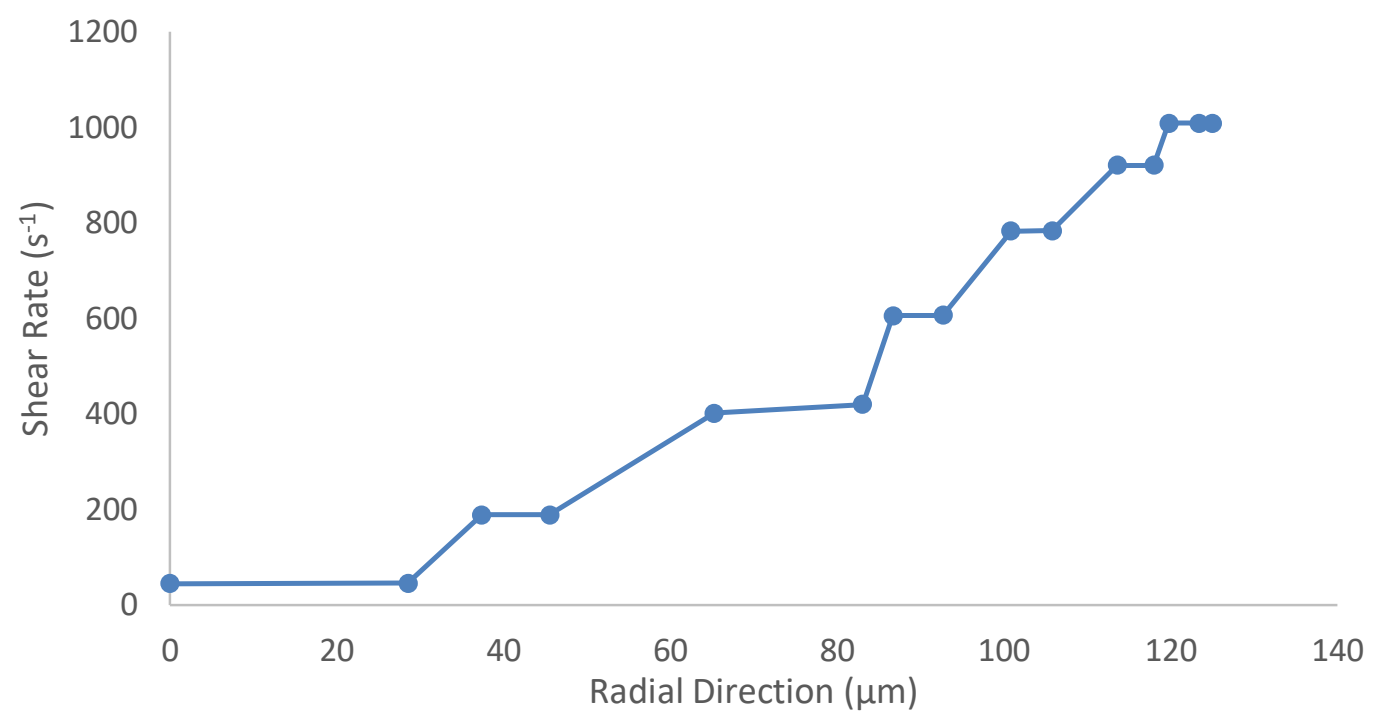

Figure 9. Shear rate through the nozzle tip.

From the shear rate analysis it is evident that the during normal operation of the printer, the ink undergoes a shear rate of shear rate of approximately $45 \mathrm{~s}^{-1}$ at the center of the nozzle up to a rate of $\sim 1000 \mathrm{~s}^{-1}$ at the wall. Based on these values, the viscosity of the fluid in the nozzle changes from approximately $0.208 \mathrm{~Pa}$ s to $0.048 \mathrm{~Pa}$ s radially through the tip, which is a difference of less than one order of magnitude.

For the data gathered through the various COMSOL simulations, the viscosity of the fluid was modeled as a non-Newtonian power-law fluid. However, it may not be necessary to consider the non-Newtonian behavior of the fluid in the numerical model of the nozzle/substrate system. According to Ubal et al., the shear-thinning effect of a non-Newtonian fluid is unnoticeable at normal operating conditions of the direct-writing system ${ }^{3}$. A decrease in the velocity of the substrate by two orders of magnitude is needed to see any substantial shear-thinning of the fluid on the printed track. A computational comparison of fluids with three different viscosities, ranging in behavior from Newtonian $(\mathrm{K}=0)$ to the non-Newtonian ink $(\mathrm{K}=0.084)$, was performed and showed no significant difference in the resultant track shape. 
Additionally, the assumption that the ink can be treated as a Newtonian fluid is also investigated using COMSOL. This is accomplished by modeling the fluid as both a Newtonian and non-Newtonian fluid and comparing the velocity profiles through the nozzle tip. Figure 10 shows this comparison.

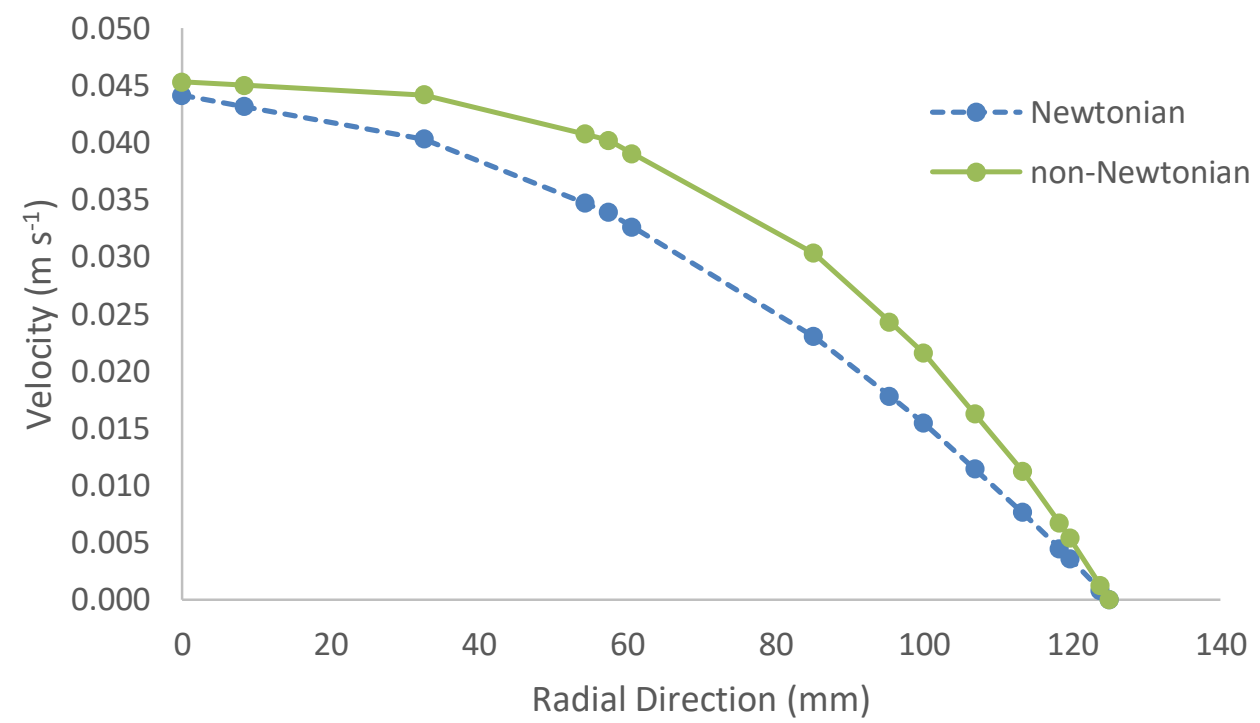

Figure 10. Newtonian versus non-Newtonian velocity profiles through the nozzle.

Treating the fluid as non-Newtonian results in a slightly larger outlet velocity, as Figure 10 shows. However, as the comparisons in Section 3.5 show, this difference does not significantly affect the model and is considered acceptable for control purposes.

\subsection{Model Validation - Nozzle}

The simulation completed in COMSOL was performed for both the actual dimensions of the nozzle and for a simple nozzle geometry (sudden contraction) that approximated the dimensions of the actual nozzle. The dimensions of the nozzle barrel are $3.74 \mathrm{~mm}$ in diameter by $9.1 \mathrm{~mm}$ long. The nozzle tip is $0.250 \mathrm{~mm}$ in diameter by $13 \mathrm{~mm}$ long. These dimensions were determined from the 3D models of the nozzles available from Nordson. Figure 11 shows the 
difference in the two nozzles modeled in COMSOL and the resultant velocity profiles for identical boundary conditions. The geometry shown is axisymmetric with respect to the z-direction. The flow of fluid is also in the positive z-direction, indicated by the gold arrow.
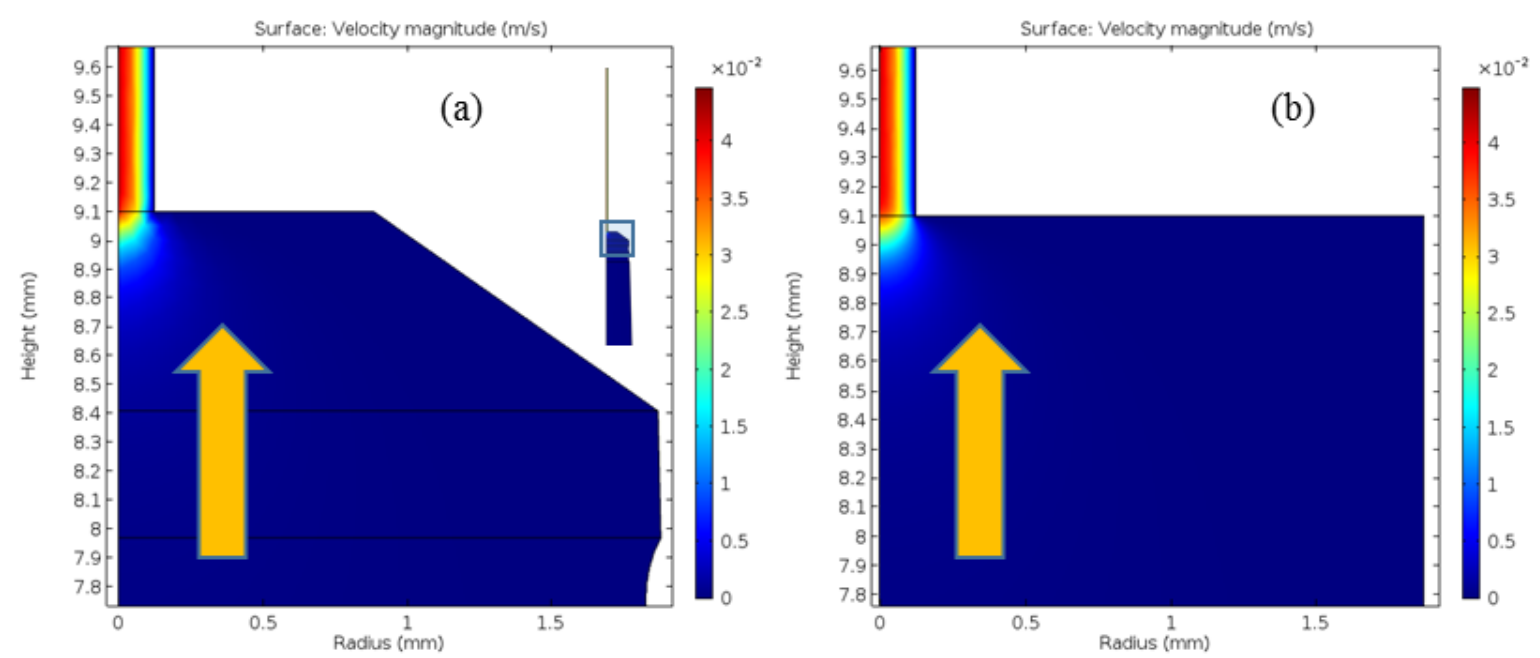

Figure 11. The nozzle model and associated velocity magnitude using a) the actual dimensions and b) the sudden contraction approximation.

The inlet and outlet boundary conditions used are $31.0 \mathrm{kPag}$ and $0 \mathrm{kPag}$, respectively. The fluid density $\rho$ is $1292 \mathrm{~kg} \mathrm{~m}^{-3}$ and the viscosity is $0.208 \mathrm{~Pa}$. The COMSOL simulation uses the same boundary conditions as the initial simulation in MATLAB, including the Newtonian behavior of the fluid. A comparison of the two velocity profiles at the tip of the nozzle is shown in Figure 12. 


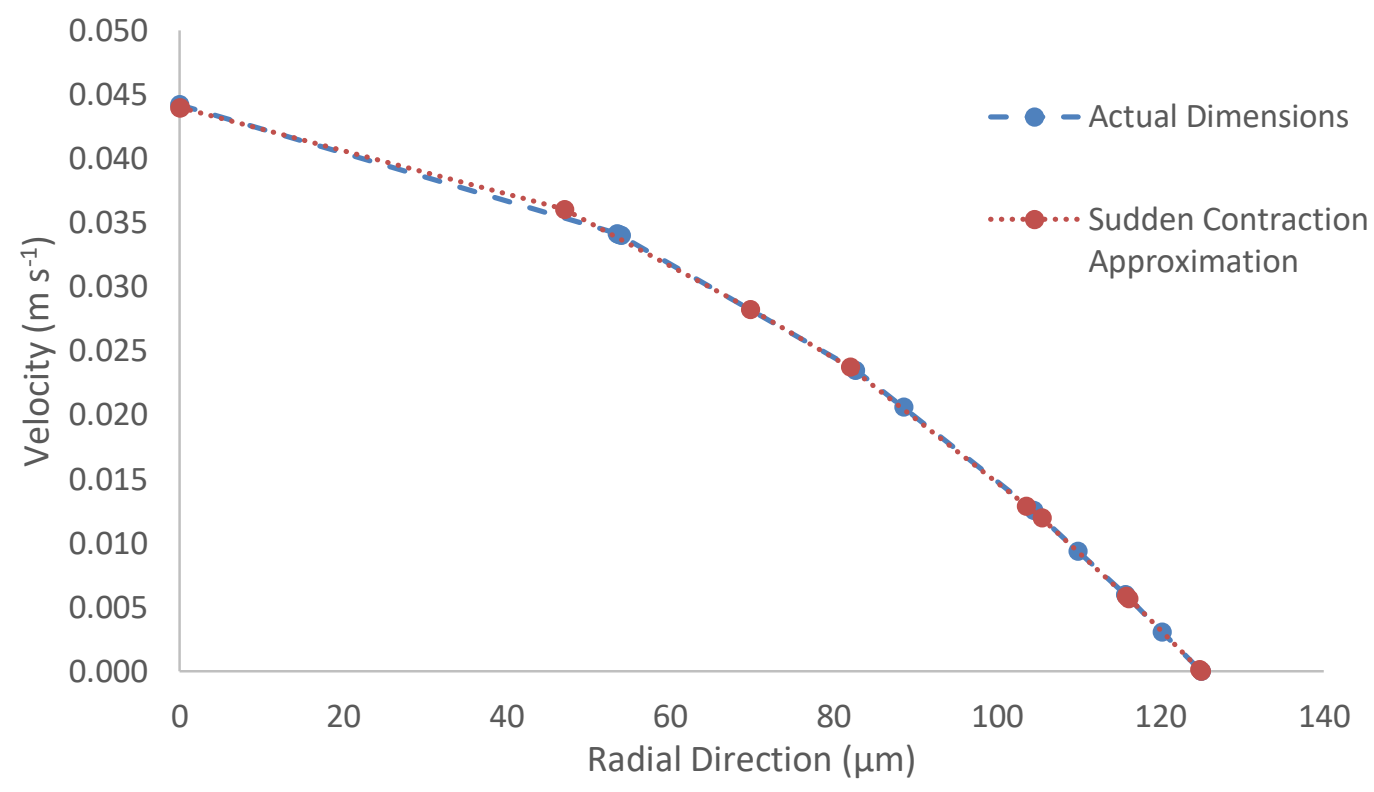

Figure 12. Comparison of the velocity profile at the tip of the nozzle between the actual dimensions of the nozzle and an approximation using a sudden contraction.

For identical operating parameters, the algebraic solution in MATLAB simulation results in an average outlet velocity of $2.24 \times 10^{-2} \mathrm{~m} \mathrm{~s}^{-1}$ while the more rigorous simulation of the sudden contraction in COMSOL yields an average outlet of $2.19 \times 10^{-2} \mathrm{~m} \mathrm{~s}^{-1}$. This difference results in a percent error of $1.89 \%$ which is considered to be satisfactory. Measurement of the outlet velocity of the ink results in an outlet velocity of $0.0247 \times 10^{-2} \mathrm{~m} \mathrm{~s}^{-1}$. The error associated between the MATLAB model and the experimentally-determined value is $9.31 \%$, which is still considered acceptable for control purposes. A table comparing all investigated inlet pressures is given in Section 3.5. 


\subsection{Nozzle Velocity and Pressure Profiles}

The effect that changing tip diameter of the nozzle has on pressure drop and velocity through the nozzle is investigated using COMSOL Multiphysics software. Figure 4 contains a diagram of the geometry used for this simulation. The geometry and dimensions of the nozzle are taken directly from the CAD files used by Nordson to design and manufacture their nozzles. In this simulation, the diameter of the tip changes at a distance $9.1 \mathrm{~mm}$ from the beginning of the nozzle. It is at this point in which the "tip" of the nozzle begins. This section is highlighted in blue in Figure 4. The tip diameter is varied between $100 \mu \mathrm{m}$, the tip size used by Torres Arango et al. $^{40}$, and $770 \mu \mathrm{m}$, the largest possible tip diameter as dictated by the nozzle available from Nordson. All other variables, including inlet and outlet pressure, ink viscosity and density, and boundary conditions are not changed.

Figure 13 shows the velocity profile across the tip of the nozzle at a distance $21 \mathrm{~mm}$ from the base of the nozzle, varied between a tip radii of $100 \mu \mathrm{m}$ and $770 \mu \mathrm{m}$. The gauges indicated correspond to different sizes provided by Nordson, with 27 gauge being the smallest diameter and 14 gauge being the largest. 


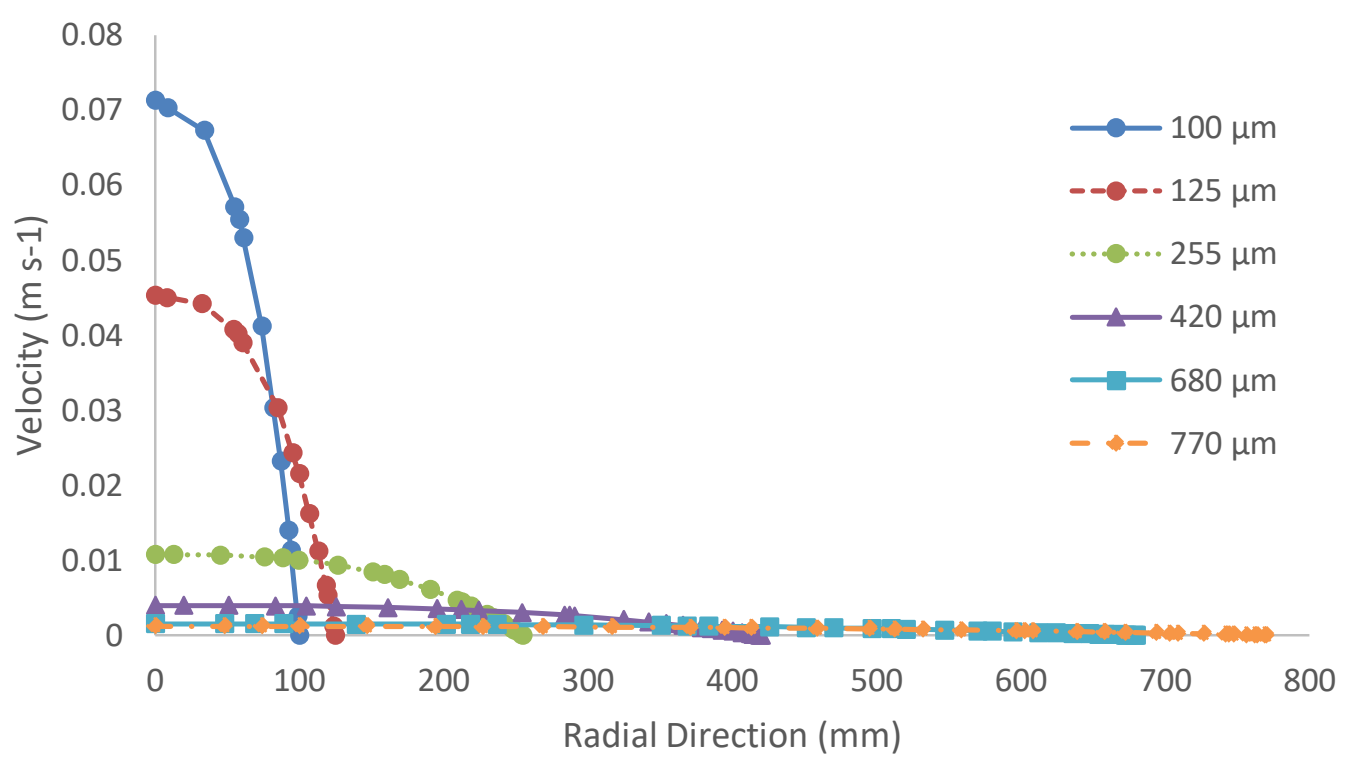

Figure 13. Velocity profiles through the nozzle as a function of tip radius.

Figure 13 shows that as the tip diameter increases, the velocity profile approaches a maximum value of $\sim 0.71 \mathrm{~m} / \mathrm{s}$ for the smallest available tip diameter. This value is, of course, dependent on the operating parameters of the simulation. Figure 13 shows that, given the same inlet and boundary conditions, a smaller tip diameter naturally allows for a larger outlet velocity. In the interest of high resolution and quality control, a smaller tip diameter is desirable. Additionally, this analysis assumes that there are no issues with the ink itself. Under certain circumstances, the ink from the nozzle will creep out of the tip without use of an applied pressure gradient. This effect is amplified for the larger tips, especially if the ink has a lower surface tension.

Figure 14 shows the pressure profile along the centerline of the nozzle for the largest and smallest diameter nozzles, the extreme cases with radii of $100 \mu \mathrm{m}$ and $770 \mu \mathrm{m}$. The axial distance at which the tip of the nozzle begins is indicated by the dashed line at $\mathrm{z}=9.1 \mathrm{~mm}$. 


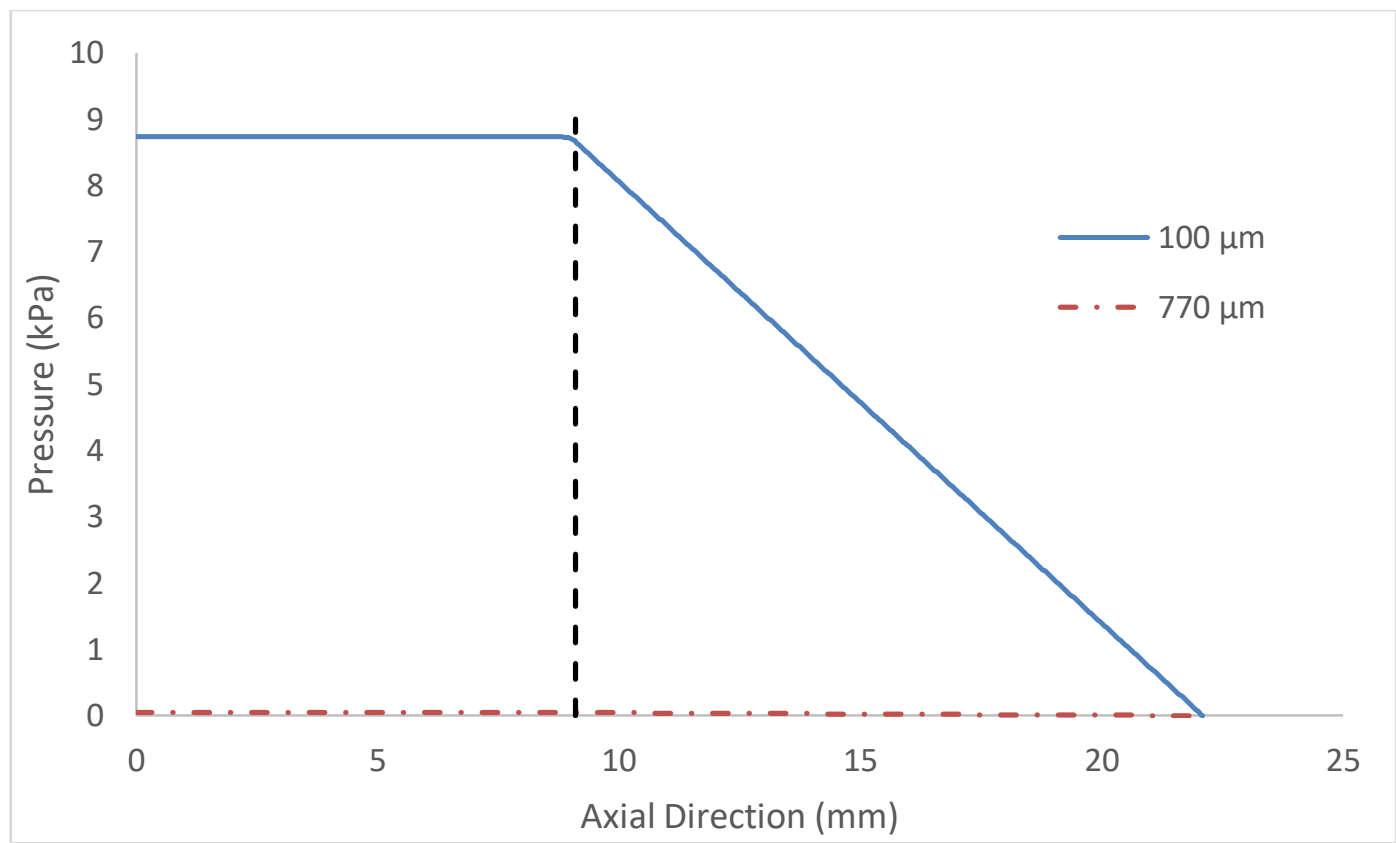

Figure 14. Pressure profile along the centerline of the nozzle.

As the radius of the tip increases, the pressure drop across the nozzle body/tip interface increases drastically for the $100 \mu \mathrm{m}$ tip. The $770 \mu \mathrm{m}$ tip has significantly less pressure drop across corresponding to its decrease outlet velocity.

Figure 15 shows the velocity profiles for axial positions at $9.1 \mathrm{~mm}$. The contraction from the main body of the nozzle to the tip occurs at $9.1 \mathrm{~mm}$. The viscosity of the fluid used in these profiles is modeled as a power-law fluid. However, the fluid is treated as a Newtonian fluid in other cases as specified. 


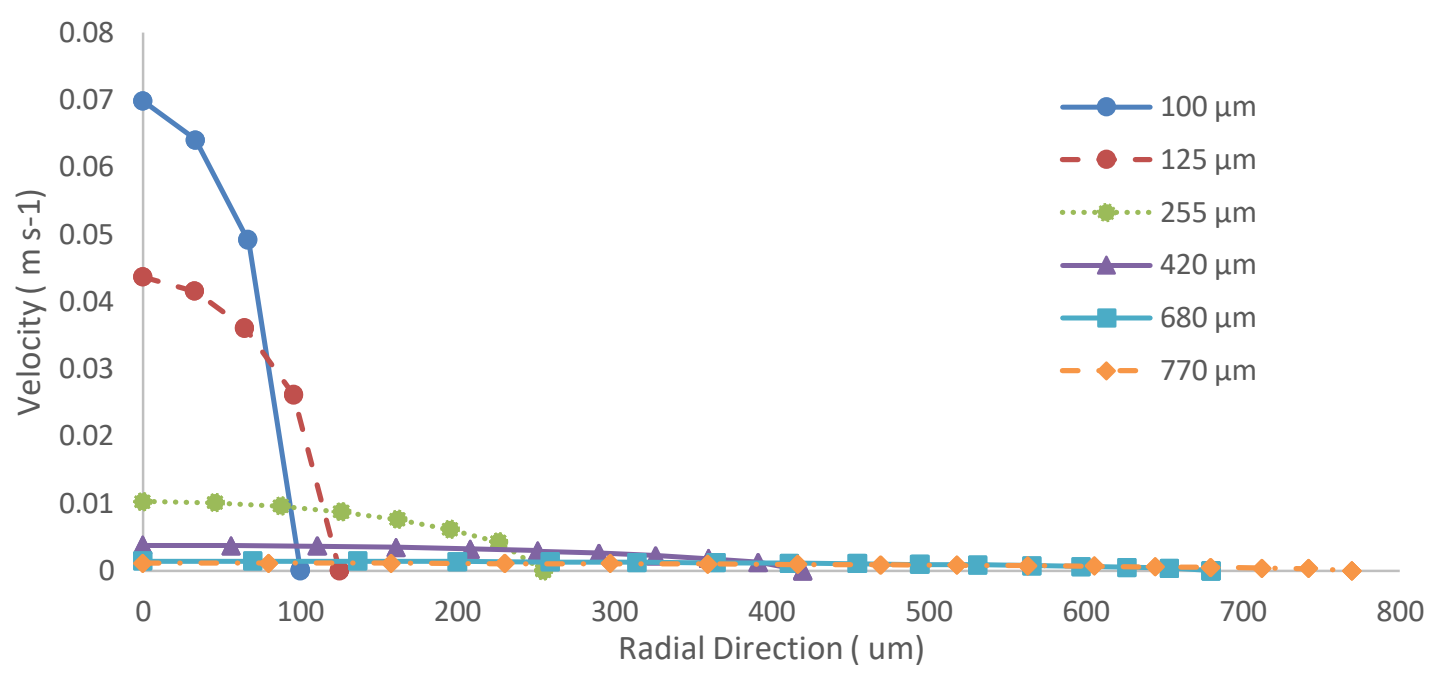

Figure 15. Velocity profile in the radial direction at axial position $9.1 \mathrm{~mm}$.

Figure 15 shows that as the tip diameter decreases, the maximum velocity increases as is expected. Note that the velocity profiles are almost identical to the corresponding profiles shown in Figure 13. This indicates that the length of the tip has no significant effect on the outlet velocity from the nozzle.

Figure 16 and Figure 17 show the pressure profiles that correspond to the same axial positions as Figure 15 and Figure 13, respectively.

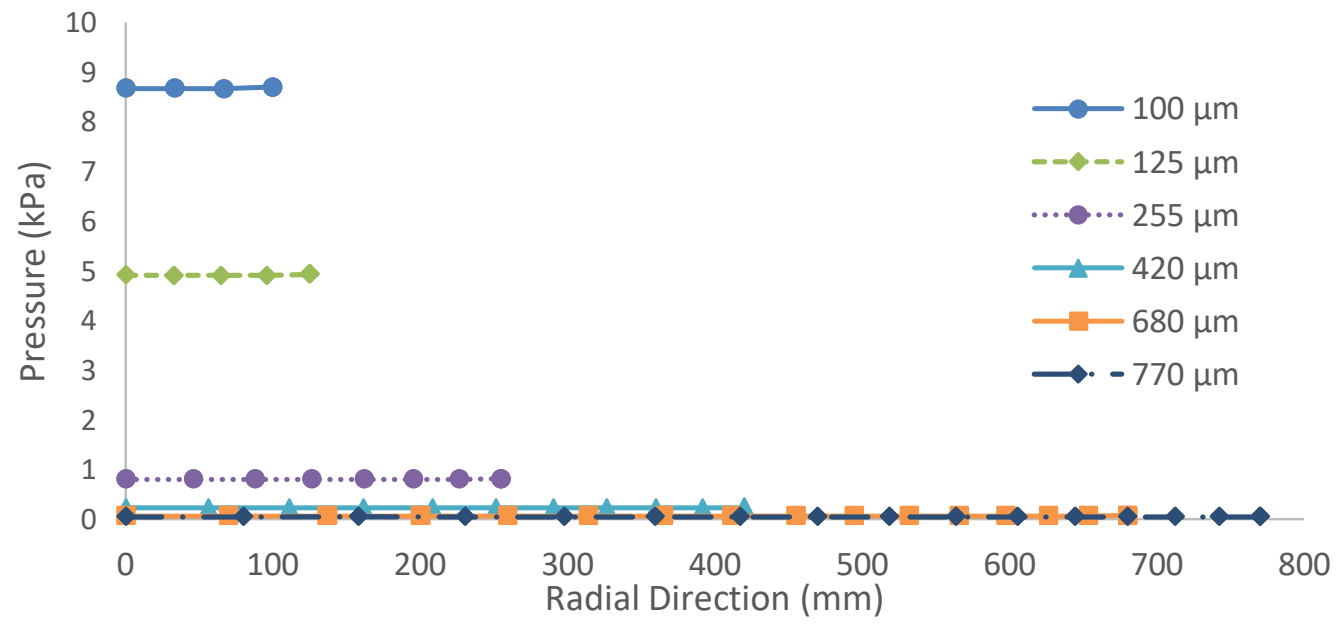

Figure 16. Pressure profile in the radial direction at axial position $9.1 \mathrm{~mm}$ 


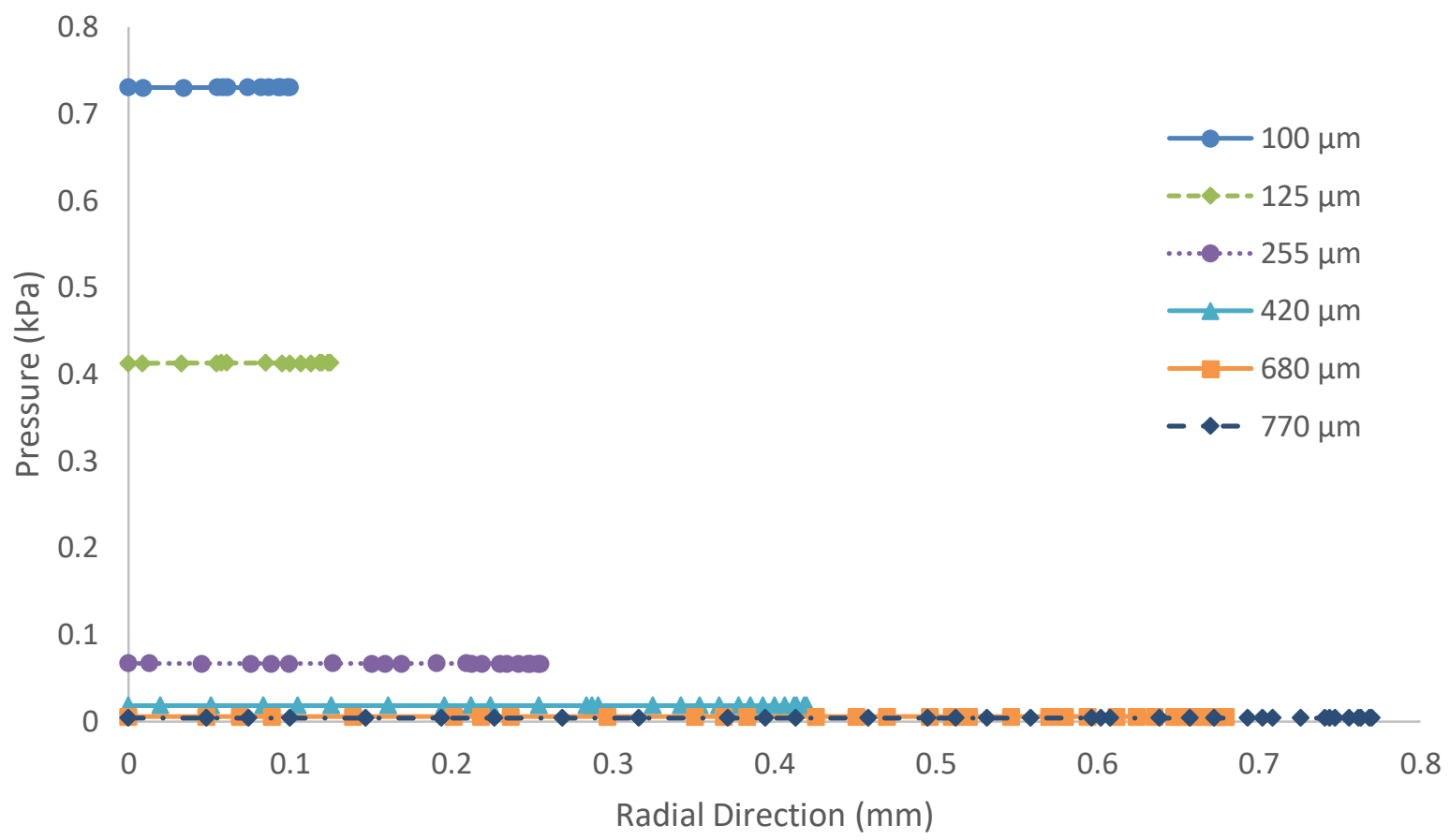

Figure 17. Pressure profile in the radial direction at axial position $21 \mathrm{~mm}$

Figure 16 and Figure 17 show that there could be considerable pressure drop as the nozzle diameter is reduced.

\subsection{Model validation - Simulation in COMSOL}

The simulation of the deposition process in COMSOL gives very good agreement with the physically printed tracks under certain conditions. Table 2 provides a summary of the different parameters used in the COMSOL model. 
Table 2. Summary of the COMSOL model parameters

\begin{tabular}{|c|c|}
\hline \multicolumn{2}{|c|}{ Fluid Properties } \\
\hline Densityair $_{\text {air }}$ & $1.20 \mathrm{~kg} \mathrm{~m}^{-3}$ \\
\hline Viscosityair & $1.79 \times \mathrm{kg} \mathrm{m}^{-1} \mathrm{~s}^{-1}$ \\
\hline Densityink & $1292 \mathrm{~kg} \mathrm{~m}^{-3}$ \\
\hline Viscosityink & $0.208 \mathrm{~kg} \mathrm{~m}^{-3}$ \\
\hline Contact Angle & $115^{\circ}$ \\
\hline Surface Tension & $3 \times 10^{-3} \mathrm{~N} \mathrm{~m}^{-1}$ \\
\hline \multicolumn{2}{|c|}{ Geometry } \\
\hline Tip Radius & $1.25 \times 10^{-4} \mathrm{~m}$ \\
\hline Tip Length & $7.50 \times 10^{-4} \mathrm{~m}$ \\
\hline Nozzle Wall Thickness & $1.25 \times 10^{-4} \mathrm{~m}$ \\
\hline Nozzle-Substrate Offset & $2.50 \times 10^{-4} \mathrm{~m}$ \\
\hline \multicolumn{2}{|c|}{ Boundary Conditions } \\
\hline Inlet Velocity & $2.05 \times 10^{-2} \mathrm{~ms}^{-1}$ \\
\hline Outlet Pressure & $0 \mathrm{kPa}$ (gauge) \\
\hline Substrate Velocity & $5.0 \times 10^{-3} \mathrm{~ms}^{-1}$ \\
\hline
\end{tabular}

The nozzle inlet velocity used in the COMSOL simulations is based off of the $27.6 \mathrm{kPa}$ (4.0 psig) pressure inlet.

With these parameters, the current solution time for a simulation of 1.5 seconds of runtime is approximately 1.5 hours. Obviously, these simulations take too long to be used for control purposes and therefore a reduced model is required. 


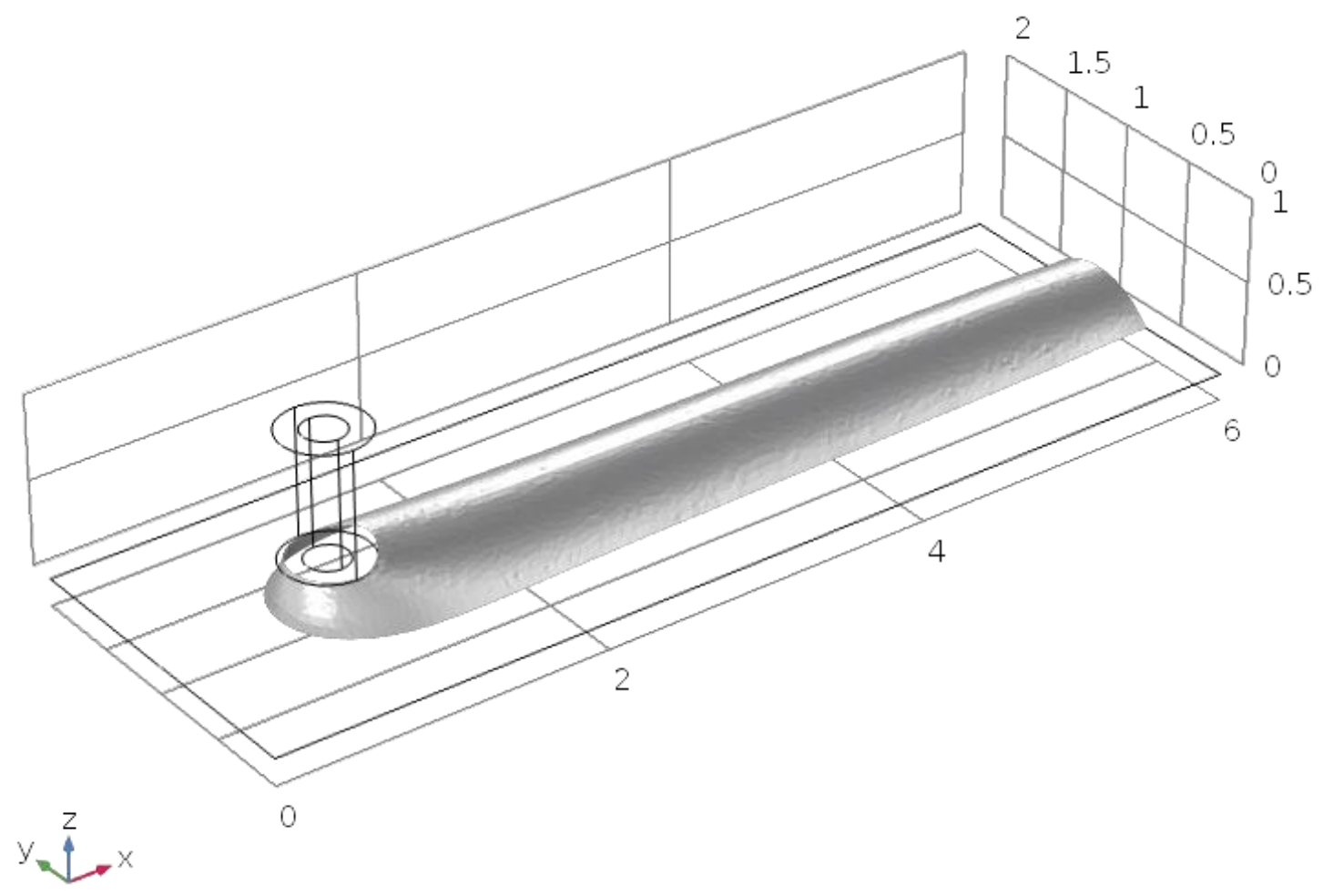

Figure 18. Track deposition model in COMSOL

Figure 18 shows the track of ink after running the deposition model in COMSOL. This particular case gives good agreement with the physical track, especially in the beginning of the deposition. A top-down view of the deposition of ink at $0.8 s$ is shown in Figure 19. 


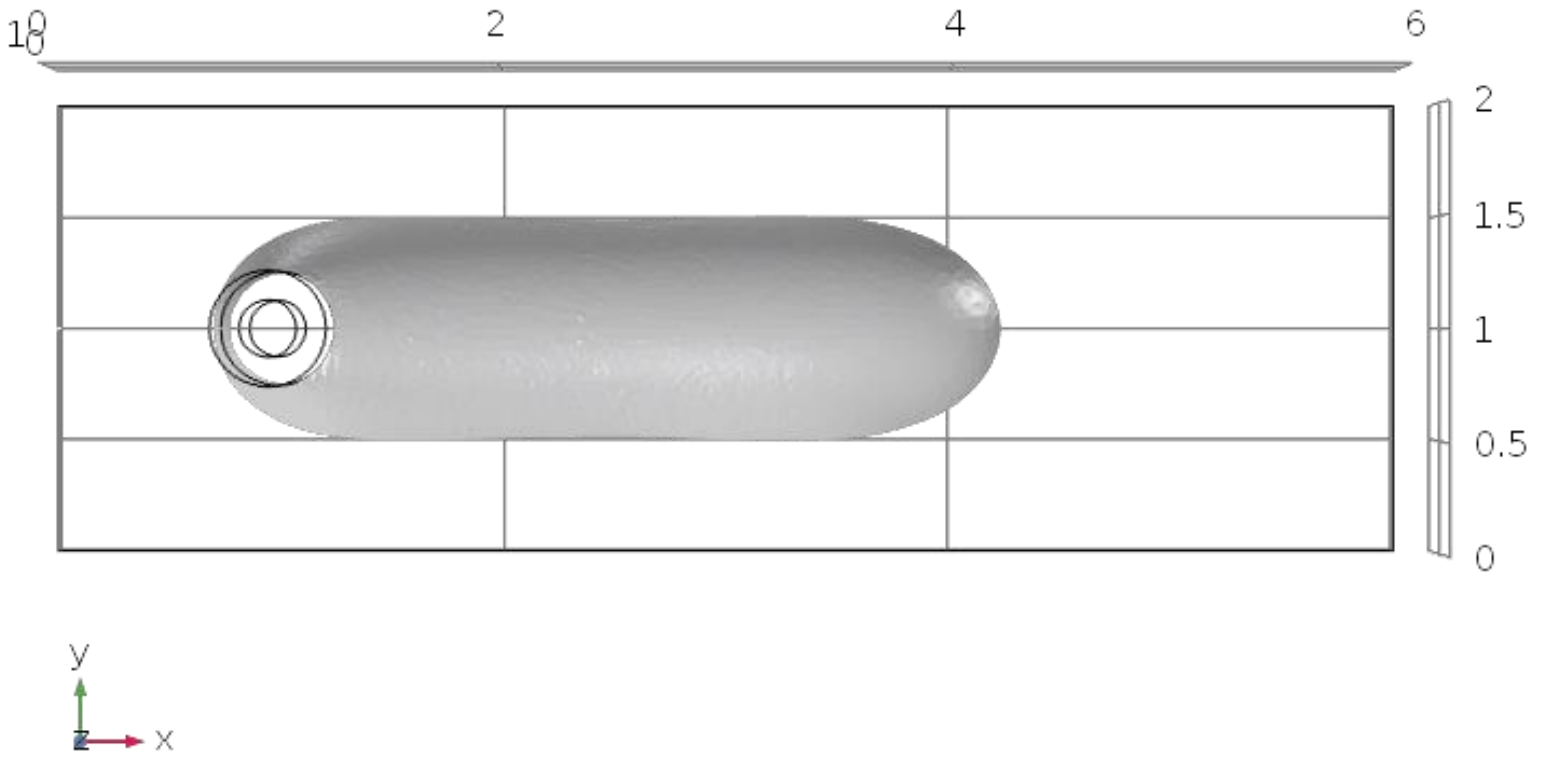

Figure 19. Track deposition at 0.8 seconds

At this point in the deposition the track width is uniform. As the deposition progresses, the track begins to taper off as it approaches the exit of the domain. This effect can be seen in Figure 20.

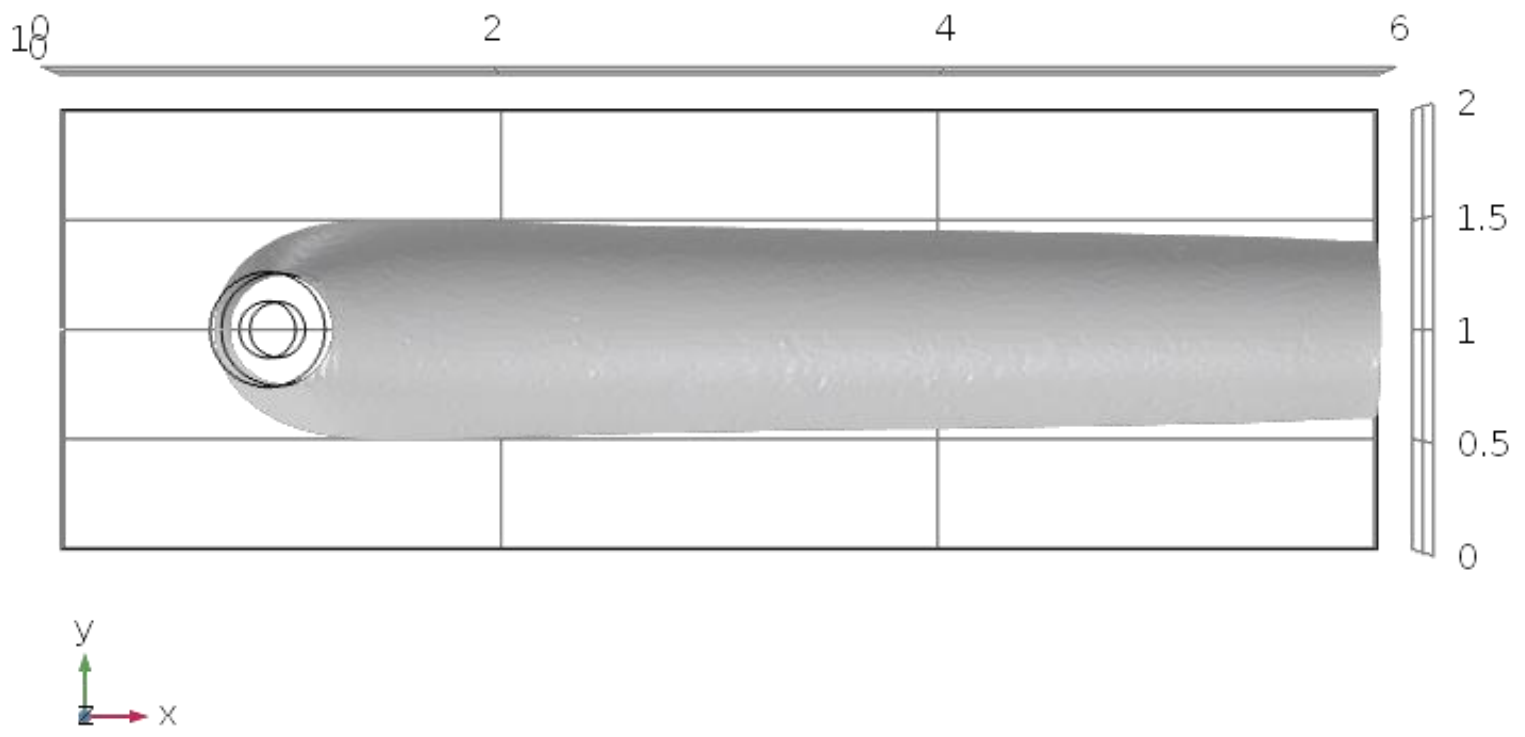

Figure 20. Track deposition at 1.5 seconds. 
The average width of the track shown in Figure 19 is approximately $1.00 \mathrm{~mm}$. As the deposition progresses, the average width decreases, down to a value of roughly $0.93 \mathrm{~mm}$. Although this value is close to the average of the corresponding physically printed track width of $0.907 \mathrm{~mm}$ the result is not necessarily correct. Since there are no disturbances accounted for in this simulation, it is expected that the track profile be of uniform width throughout the entire domain. The difference in track widths results in a percent error of $2.54 \%$. Additional images of the domain and deposition are available in Appendix A.

\subsection{Model Validation - Simulation in MATLAB}

Like the case in COMSOL, the deposition model created in MATLAB gives a very good agreement with the physically printed track in some of the cases of interest. Table 3 provides a summary of the different parameters used in the various simulations.

Table 3. Summary of the MATLAB model parameters

\begin{tabular}{|c|c|}
\hline \multicolumn{2}{|c|}{ Fluid Properties } \\
\hline Density & $1292 \mathrm{~kg} \mathrm{~m}^{-3}$ \\
\hline Viscosity & $0.208 \mathrm{~kg} \mathrm{~m}^{-3}$ \\
\hline Contact Angle & $65.7^{\circ}$ \\
\hline \multicolumn{2}{|c|}{ Pressure } \\
\hline Inlet Pressure & Variable \\
\hline Outlet Pressure & $1.01325 \times 10^{5}$ \\
\hline \multicolumn{2}{|c|}{ Nozzle Parameters } \\
\hline Barrel Radius & $3.8 \times 10^{-3} \mathrm{~m}$ \\
\hline Barrel Length & $5.0 \times 10^{-2} \mathrm{~m}$ \\
\hline Tip Radius & $1.25 \times 10^{-4} \mathrm{~m}$ \\
\hline Tip Length & $1.3 \times 10^{-2} \mathrm{~m}$ \\
\hline Nozzle Writing Speed & $5.0 \times 10^{-3} \mathrm{~m} \mathrm{~s}^{-1}$ \\
\hline
\end{tabular}


Aside from the inlet pressure, the parameters used in each simulation are kept constant. The contact angle given in Table 3 is the compliment to the angle used in COMSOL. This value is the experimentally determined value; COMSOL requires the complimentary angle to solve correctly.

Although the nozzle offset is not used in the MATLAB model, it is worth mentioning since it can have a direct effect on the deposition process. However, the effect that this ratio has on the deposition process is not explored in this work. The offset was kept at a constant diameter-toheight ratio of one $(D / h=1)$. At inlet pressures of $20.7 \mathrm{kPa}(3.0 \mathrm{psi})$ and below, the printer had trouble printing solid lines of ink. Therefore, the MATLAB model is not used to consider depositions at or below that point.

Table 4 shows additional comparisons of outlet velocities using different inlet pressures. The model has good agreement with some of the inlet pressures studied in this work.

Table 4. MATLAB model versus physical nozzle outlet comparison

\begin{tabular}{|c|c|c|c|}
\hline $\begin{array}{l}\text { Inlet Pressure } \\
(\mathbf{k P a})\end{array}$ & $\begin{array}{l}\text { Actual Outlet } \\
\text { Velocity (m/s) }\end{array}$ & $\begin{array}{l}\text { Model Outlet } \\
\text { Velocity (m/s) }\end{array}$ & $\begin{array}{l}\text { Absolute } \\
\text { Percent Error } \\
(\%)\end{array}$ \\
\hline 24.1 & 0.017 & 0.0174 & 2.35 \\
\hline 27.6 & 0.0198 & 0.0199 & 0.51 \\
\hline 31.0 & 0.0247 & 0.0224 & 9.31 \\
\hline 34.5 & 0.032 & 0.0249 & 22.2 \\
\hline
\end{tabular}

\subsection{Model Validation - Printed Track}

Further validation of the MATLAB model and the rigorous CFD simulations is completed with comparisons to physically printed tracks of ink. In all cases, the tracks are printed using a write speed of $5 \mathrm{~mm} \mathrm{~s}^{-1}$ unless otherwise specified. The inks were created using the method 
described in the Methodology and were printed using the Nordson 3-axis automated system. The readout on the DW printer's pressure controller is given in units of psi, so the inlet pressure is varied by intervals of $3.45 \mathrm{kPa}(0.5 \mathrm{psi})$. The track shown in Figure 21 is printed using an inlet pressure of $27.6 \mathrm{kPa}(4.0 \mathrm{psig})$.

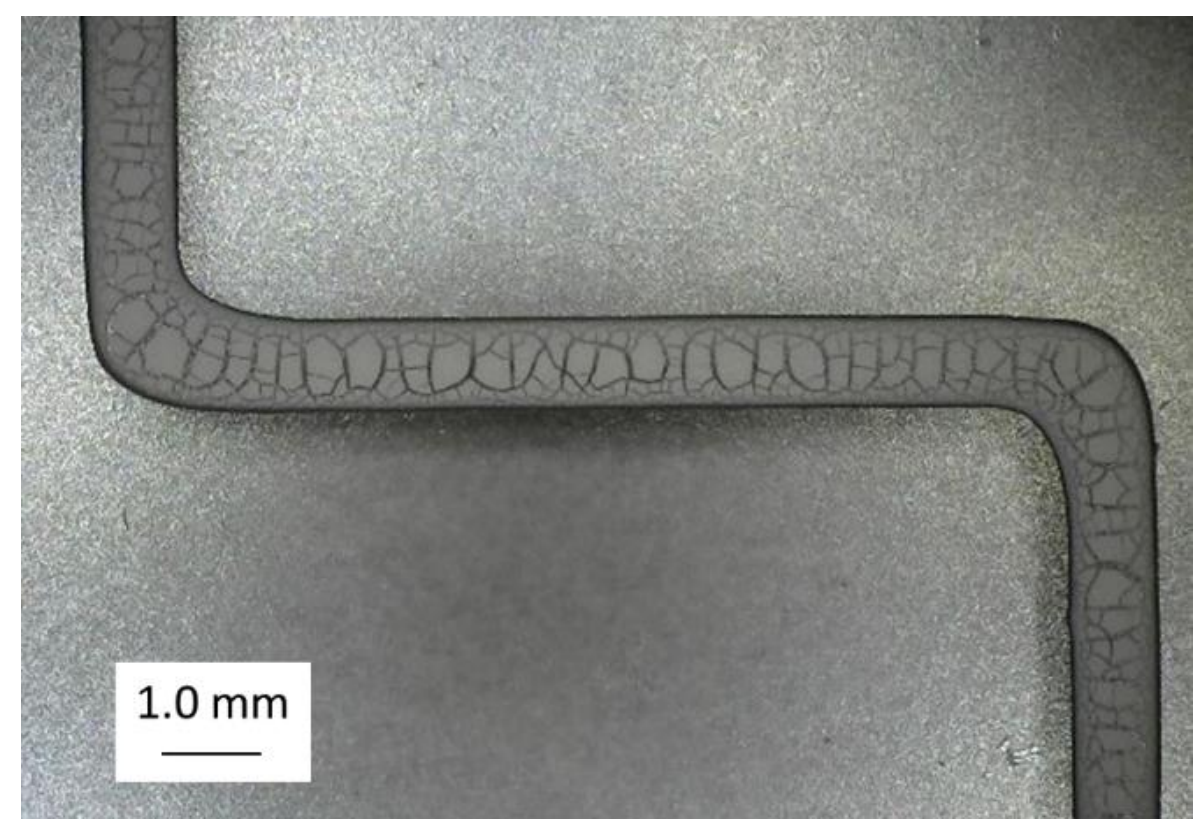

Figure 21. Track of printed ink. Inlet Pressure of $27.6 \mathrm{kPa}$

Figure 22 shows a track of ink printed with an inlet pressure of $31.0 \mathrm{kPa}(4.5 \mathrm{psi})$. Figure 23 shows a track of ink printed with an inlet pressure of $34.5 \mathrm{kPa}(5.0 \mathrm{psi})$ and Figure 24 shows a track of ink printed with an inlet pressure of $24.1 \mathrm{kPa}(3.5 \mathrm{psi})$. 


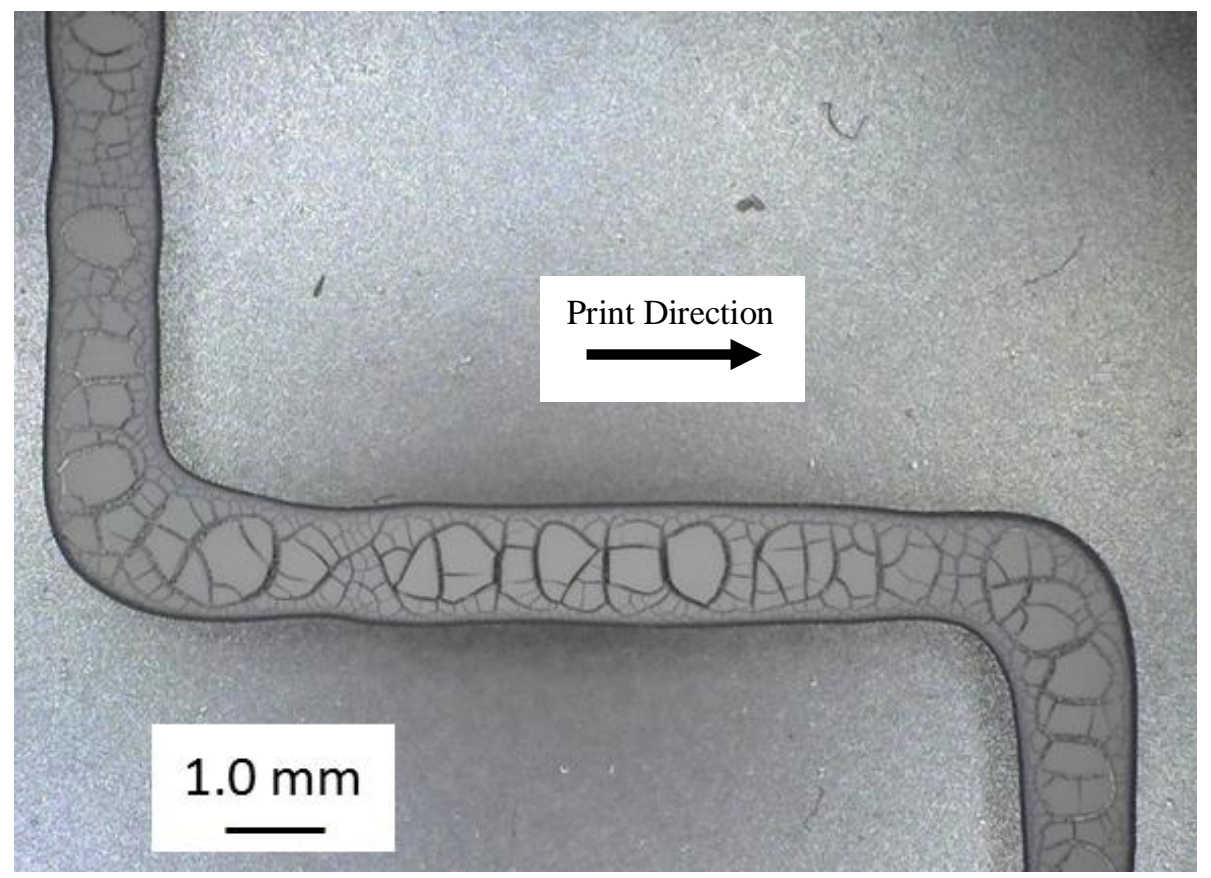

Figure 22. Track of printed ink. Inlet Pressure of $31.0 \mathrm{kPa}$

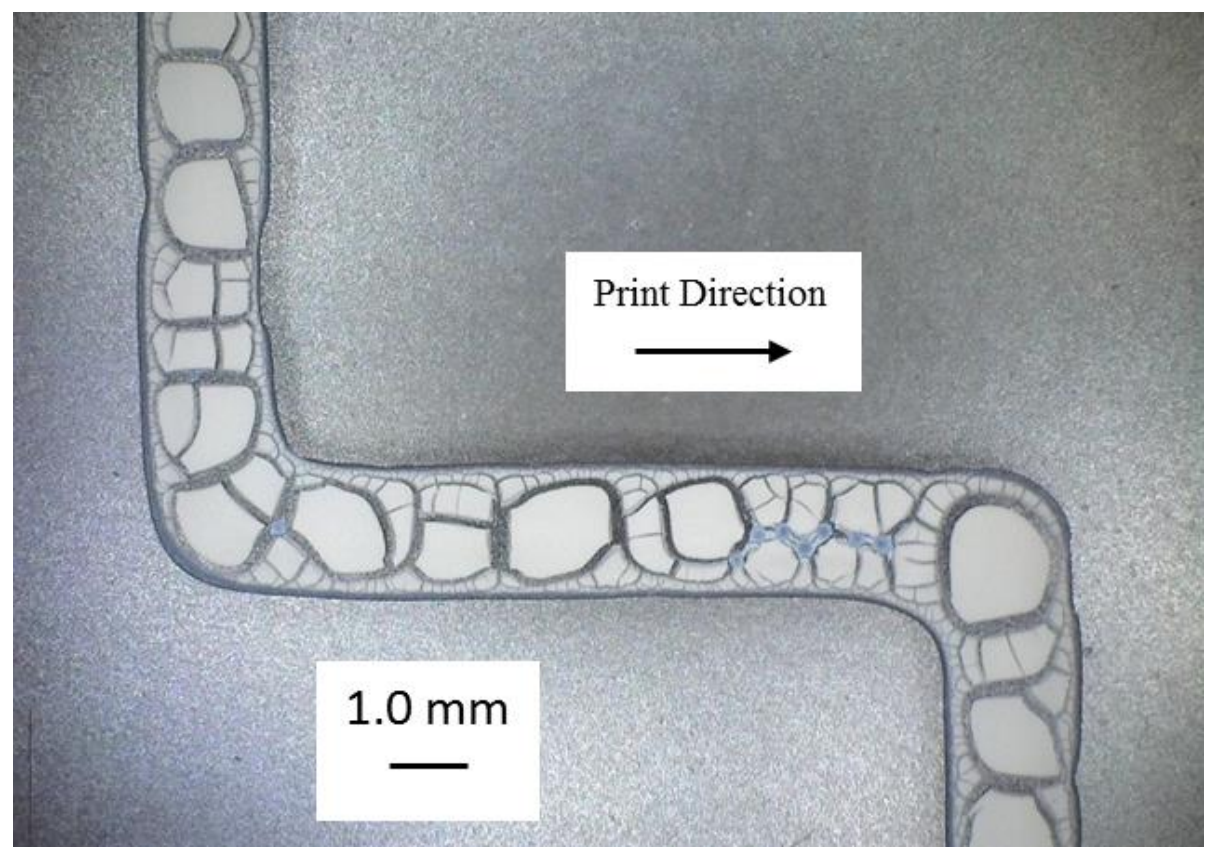

Figure 23. Track of printed ink. Inlet Pressure of $34.5 \mathrm{kPa}$ 


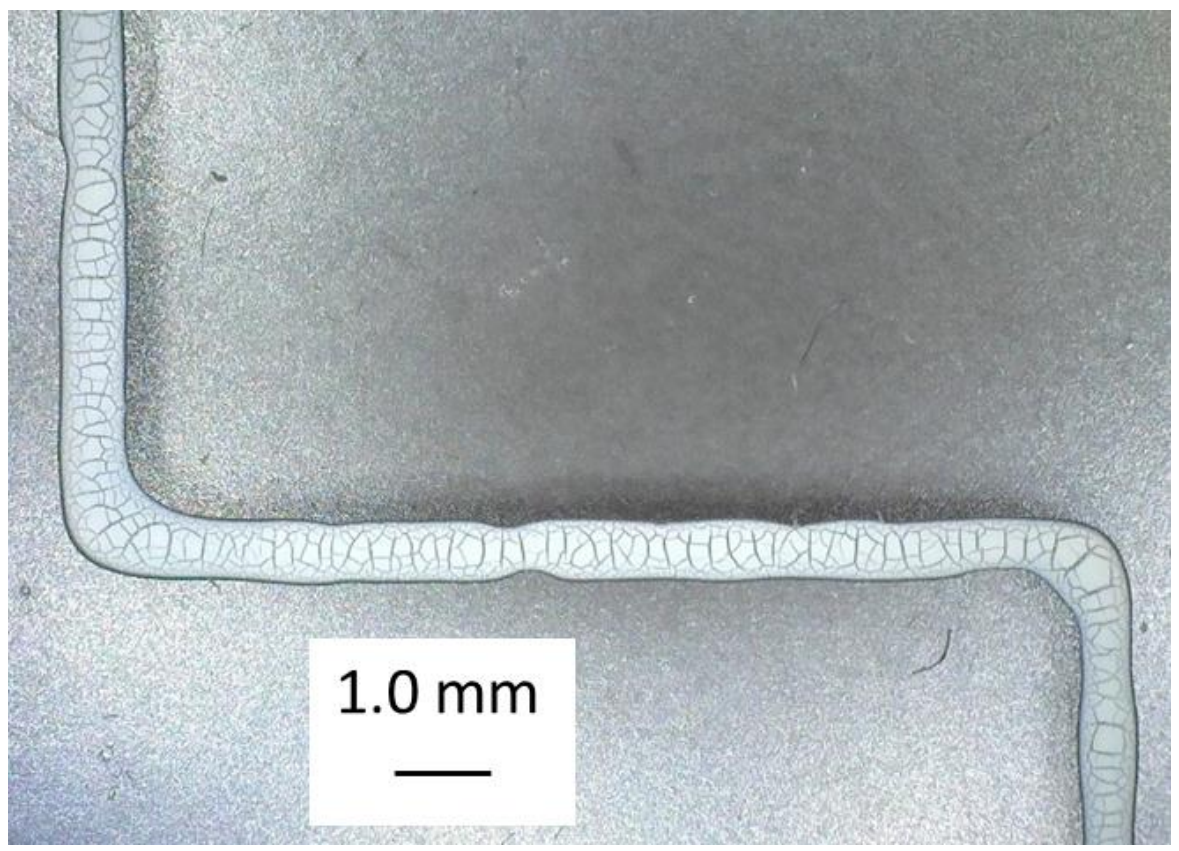

Figure 24. Track of printed ink. Inlet Pressure of $24.1 \mathrm{kPa}$

From these figures, it is evident that the track width becomes thinner as the inlet pressure is decreased at the same writing speed as would be expected. Below inlet pressures of $24.1 \mathrm{kPa}$, the printer had trouble depositing the samples of ink. These instances result in tracks of fluid that are largely broken and uneven. Figure 25 shows a sample of ink printed with an inlet pressure of $20.7 \mathrm{kPa}$ (3.0 psi). From Figure 25 it is clear that the track was not properly printed. Additional attempts at printing with this inlet pressure resulted in similar outcomes. It is for this reason that instances with inlet pressures at or below $20.7 \mathrm{kPa}$ are not investigated. 


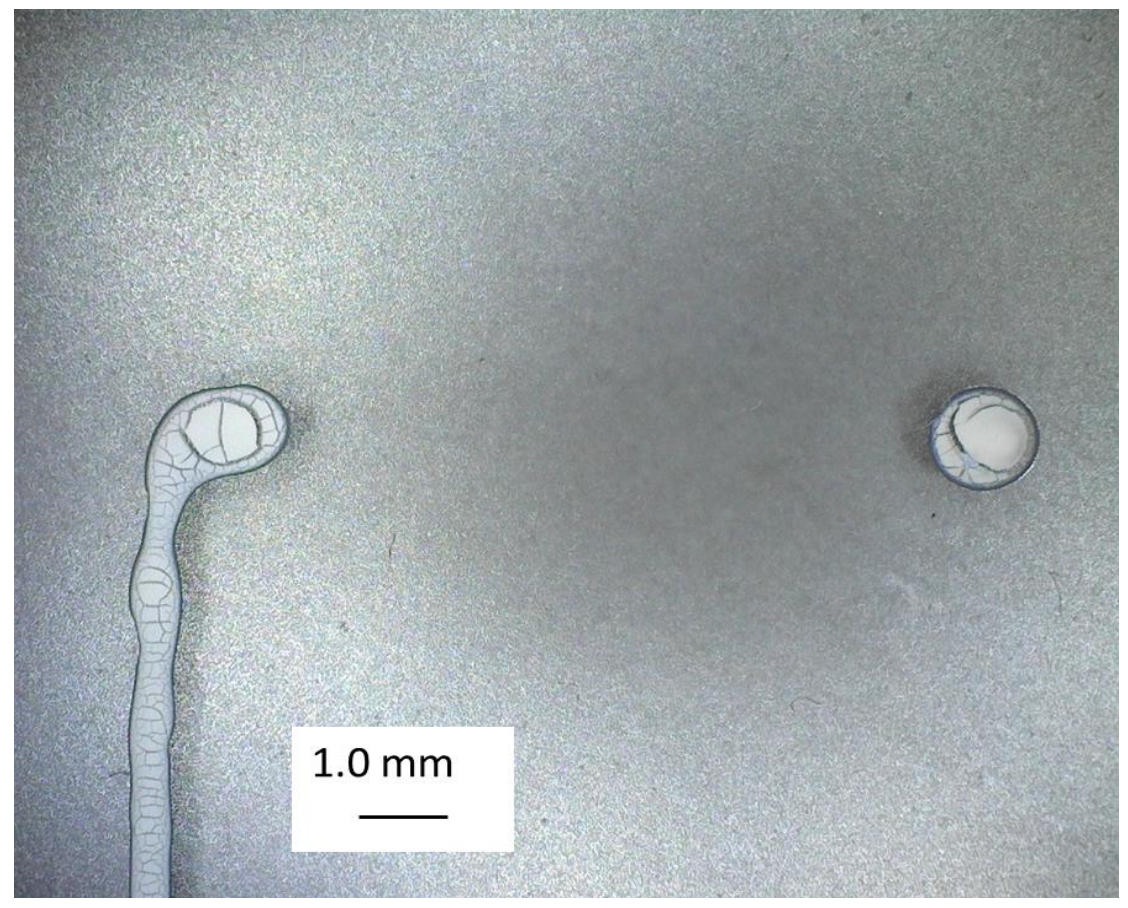

Figure 25. Track of ink printed with an inlet pressure of $20.7 \mathrm{kPa}$

Figure 26 shows the change in track width as the deposition takes place. Specifically, this data is recorded using the measurement feature available in the Dino-Lite Edge digital microscope. The length reported follows the print direction indicated in each figure. Measurements are taken in approximately the same places for each fluid track. 


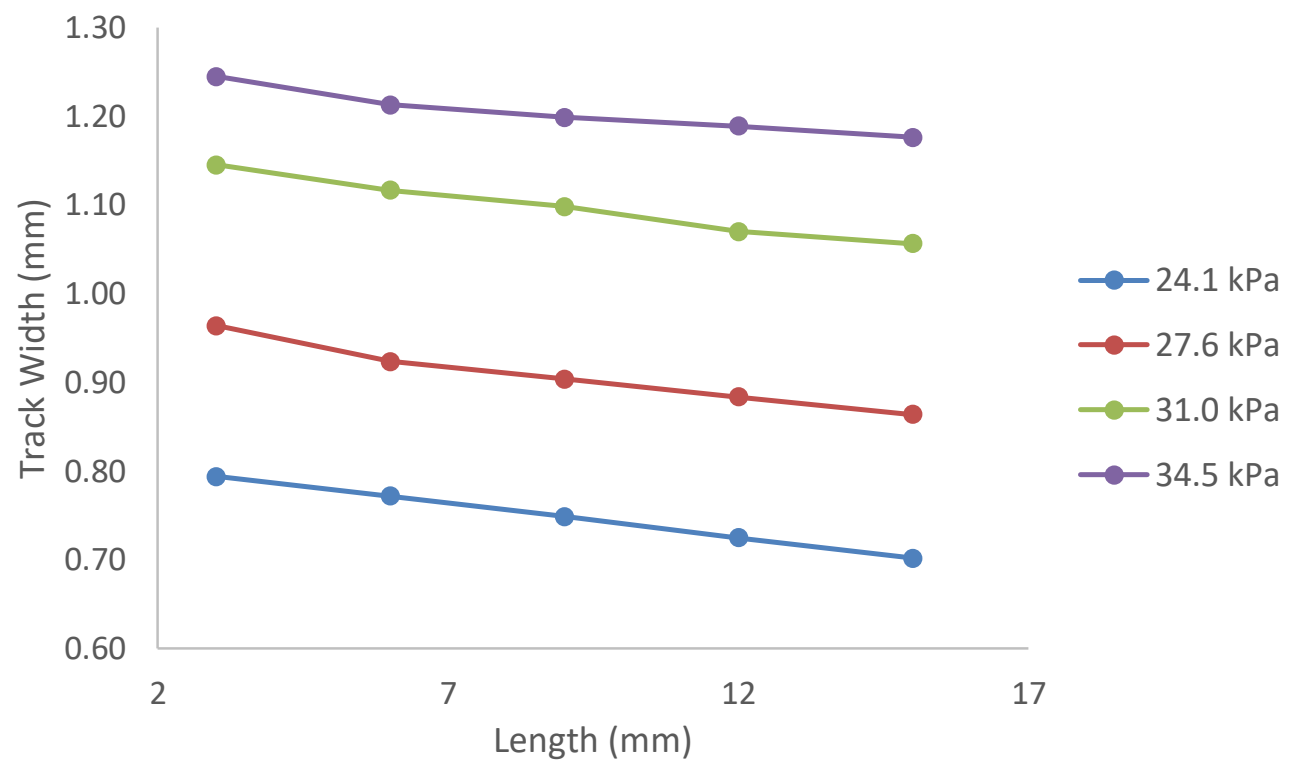

Figure 26. Change in track width for various inlet pressures.

Depending on the product being printed, the amount that the width changes by may not be significant to the integrity of the final product. However, for quality purposes, this necessitates the use of a controller to prevent the decrease in track width as the deposition takes place.

Table 5 shows the comparison of the track width between the MATLAB model and the actual data. It is observed that the error is within $+/-15 \%$, which is considered to be acceptable since the model has a number of assumptions and it is intended for use in control studies.

Table 5. MATLAB Model versus physical track width comparisons

\begin{tabular}{|c|c|c|c|}
\hline $\begin{array}{l}\text { Inlet Pressure } \\
(\mathbf{k P a})\end{array}$ & $\begin{array}{l}\text { Model Width } \\
(\mathbf{m m})\end{array}$ & $\begin{array}{l}\text { Actual Width } \\
\text { (averaged) }(\mathbf{m m})\end{array}$ & $\begin{array}{l}\text { Absolute } \\
\text { Percent Error } \\
(\%)\end{array}$ \\
\hline 24.1 & 0.859 & 0.794 & 14.8 \\
\hline 27.6 & 0.918 & 0.907 & 1.14 \\
\hline 31.0 & 0.974 & 1.097 & 6.99 \\
\hline 34.5 & 1.027 & 1.204 & 14.7 \\
\hline
\end{tabular}




\subsection{Proportional Control - MATLAB}

During the deposition process, the track width may change because of a number of reasons such as ink inhomogeneity, printer characteristics, pressure control system, height of the ink column, especially for large-scale industrial system, etc. Therefore it will be desired to maintain the width by rejecting the disturbances (tracking control). It may also be desired to have different track width at different locations (servo control). In this study, servo control performances of the direct-write process are studied. Since the process model could be represented by algebraic equations, it results in a pure-gain system where the change in the output (width) following a change in the input (pressure or writing speed) is instantaneous. For such systems, P-only control is adequate to control the track width during on-line operation of the printer. In order to determine the value of the gain, the inlet pressure was increased from $27.6 \mathrm{kPa}$ to $31.0 \mathrm{kPa}$ in a single step. This plot is shown in Figure 27.

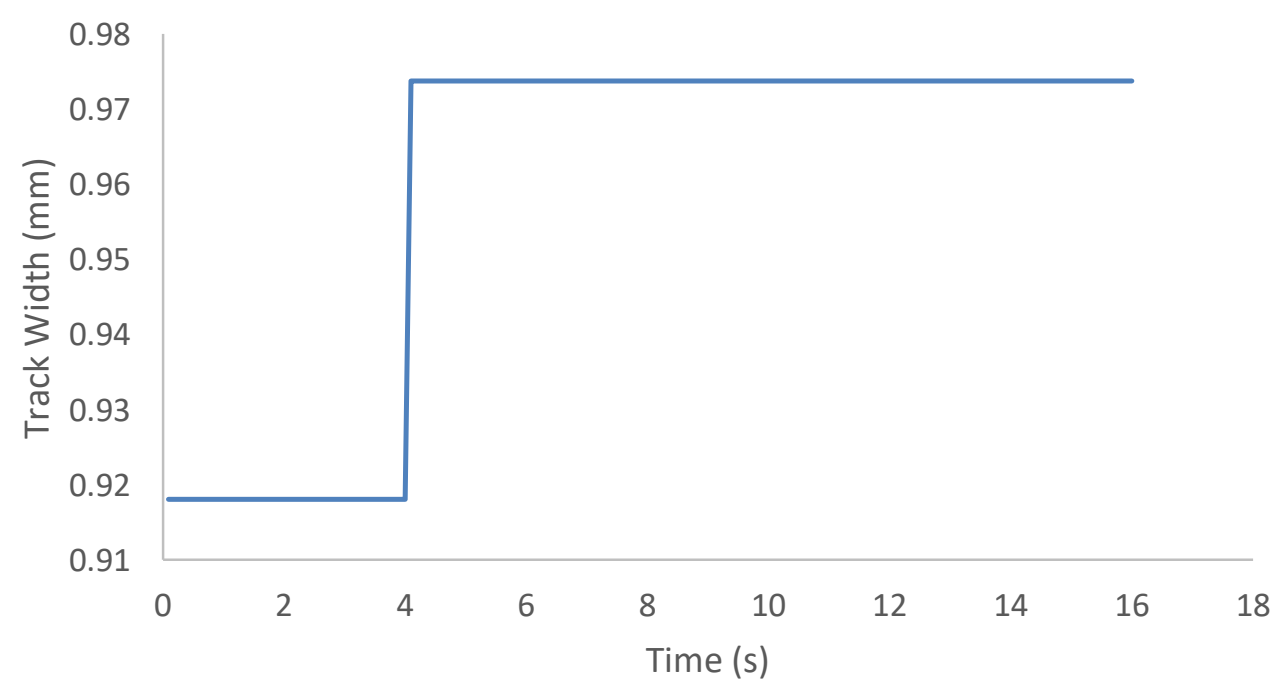

Figure 27. Proportional control parameter fitting

The data collected shown in Figure 27 is collected from a step change in inlet pressure. The step change occurs at 4 seconds on the graph, with the model being at steady state prior to that 
point. This step change results in a change in $\Delta w=0.0556 \mathrm{~mm}$, which is used for calculating the gain.

Figure 28 shows the change in track width using the experimentally-determined controller parameters. The adjustment in track width comes from a change in the inlet pressure of the nozzle.

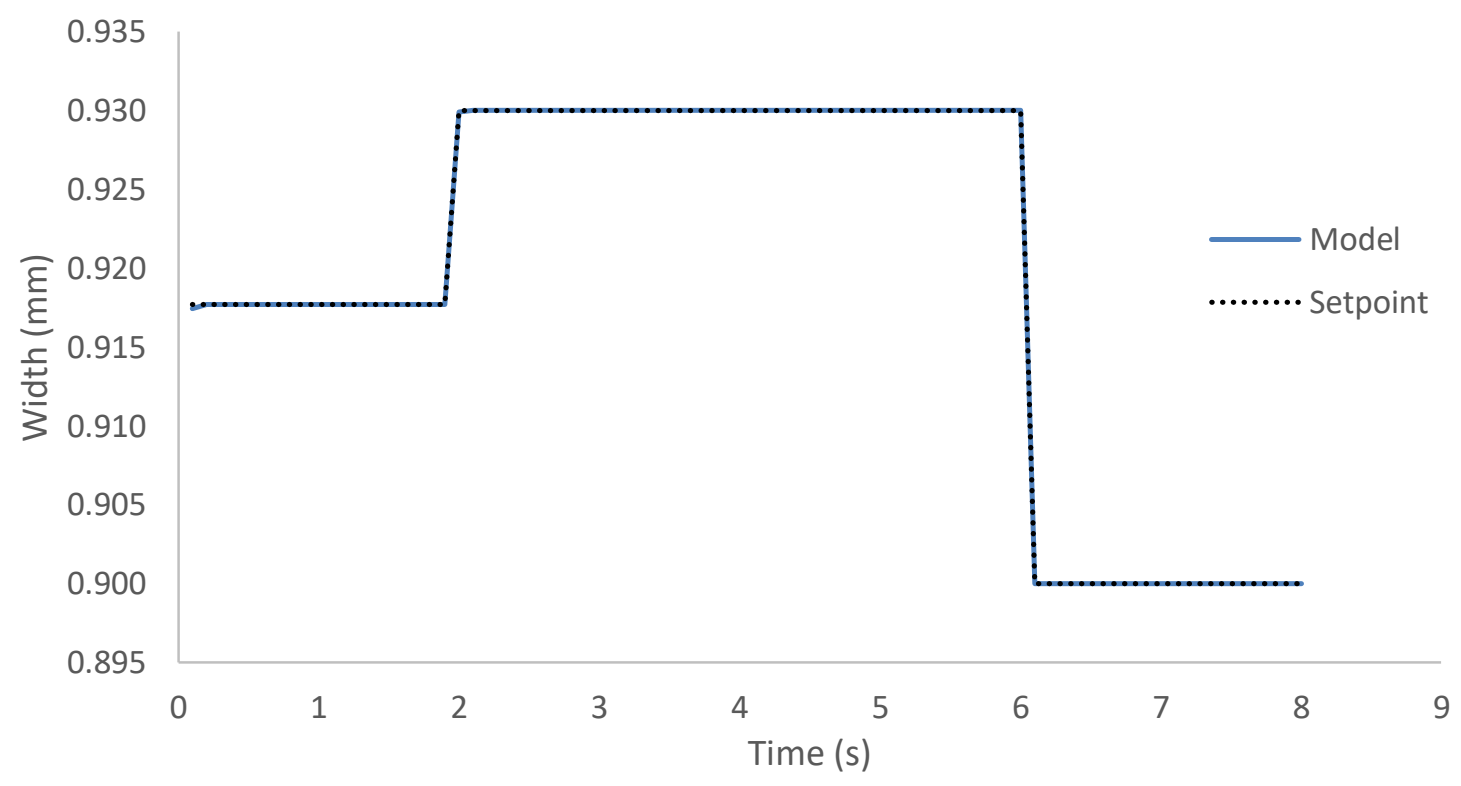

Figure 28. Change in setpoint with inlet pressure adjustment.

From Figure 28, it is evident that as the change in setpoint can be achieved rapidly by adjusting the printer inlet pressure.

Unfortunately, the printer used in this research does not allow for the inlet pressure to be changed and therefore these results cannot be substantiated with physical experiments. However, it is worth noting that, from a manufacturing standpoint, the track width adjustment using the change in inlet pressure would be more advantageous than changing the writing speed since it allows for the width to be maintained or changed without slowing down the manufacturing process. Therefore investigating this result with a direct-write printer that can change the inlet pressure during operation is a worthwhile pursuit. 


\section{Conclusions}

In this work, the pattern morphology of a track of fluid printed through the direct-write process are investigated and implementation of a control strategy to control the width of the track being printed are conducted. This is accomplished by studying the deposition process using a direct-write 3D printer and by simulating the deposition process using MATLAB and COMSOL Multiphysics software.

Through this research, the accuracy of the COMSOL model was validated to an extent. The flow of fluid through a sudden contraction approximation is validated. Using comparisons to physical depositions, the track deposition model is also validated. Although the error in the model is found to be within $2.5 \%$ regarding the experimental data, changes to the model are warranted for design purposes.

Sudden contraction approximation is made while developing the MATLAB model of the nozzle. Results from the nozzle model created in MATLAB compare well with the COMSOL results. The error in the MATLAB deposition model is found to be within $+/-15 \%$ with respect to the experimental data, which is considered to be accurate enough for control studies.

It was observed that the track width is strongly affected by the inlet pressure of the nozzle and therefore the nozzle inlet pressure can be manipulated to maintain the width at a desired value or to change it. Since the process can be considered to be a pure-gain process, a P-only controller is adequate. It is observed that the P-only controller results in perfect control of the width. 


\section{References}

\footnotetext{
${ }^{1} \mathrm{~W}$. Seufzer, Additive Manufacturing Modeling and Simulation, NASA Langley Research Center, Virginia: NASA/TM-2014-218245, 2014.

${ }^{2}$ L. Murr, S. Gaytan, D. Ramirez, E. Martinez, J. Hernandez, K. Amato, P. Shindo, F. Medina and R. Wicker, "Metal Fabrication by Additive Manufacturing Using Laser and Electron Beam Melting technologies," Journal of Materials Science \& Technologies, vol. 28, no. 1, pp. 1-14, 2012.
}

${ }^{3}$ Ubal SS, Xu BB, Derby BB, Grassia PP. Continuous Deposition of a Liquid Thread onto a Moving Substrate. Numerical Analysis and Comparison With Experiments. ASME. J. Fluids Eng. 2012;134(2):021301-021301-17. doi:10.1115/1.4005668.

${ }^{4}$ K. K. B. Hon, L. Li, and I. M. Hutchings, Direct writing technology - Advances and developments, CIRP. Ann.-Manuf. Techn. 57 (2008) $601-220$.

5 A. Pique, and D. B. Chrisey, Direct-Write Technologies for Rapid Prototyping Applications: Sensors, Electronics and Integrated Power Sources, (2002) Academic Press.

${ }^{6}$ J. A. Lewis, and G. M. Gratson, Direct writing in three dimensions, Mater. Today 7 (2004) 3239.

${ }^{7}$ G. M. Gratson, M. Xu, and J. A. Lewis, Direct writing of three - dimensional webs, Nature 428 (2004) 386.

${ }^{8}$ J. Cesarano, R. Segalman, and P. Calvert, Robocasting provides moldless fabrication from slurry deposition, Ceram. Ind. 184 (1998) $94-100$.

${ }^{9}$ Q. Xu, Y. Lv, C. Dong, T. S. Sreeprased, A. Tian, H. Zhang, Y. Tang, Z. Yu, and N. Li, Threedimensional micro/nanoscale architectures: fabrication and applications, Nanoscale 7 (2015) 10883 - 10895 .

${ }^{10}$ J. R. Raney, and J. A. Lewis, Printing mesoscale architectures, MRS Bull. 40 (2015) 943 - 950.

${ }^{11}$ J. A. Lewis, J. E. Smay, J. Stuecker, J. Cesarano III, Direct ink writing of three - dimensional ceramic structures, J. Am. Ceram. Soc. 89 (2006) 3599 - 3609.

12 J. C. Conrad, S. R. Ferreira, J. Yoshikawa, R. F. Shepherd, B. Y. Ahn, and J. A. Lewis, Designing colloidal suspensions for directed materials assembly, Curr. Opin. Colloid In. 16 (2011) $71-79$.

13 J. A. Lewis, Colloidal processing of ceramics, J. Am. Ceram. Soc. 83 (2000) 2341 - 2359. 
${ }^{14}$ S. L. Morissette, J. A. Lewis, J. Cesarano III, D. B. Dimos, and T. Baer, Solid freeform fabrication of aqueous alumina - poly (vinyl alcohol) gelcasting suspensions, J. Am. Ceram. Soc. 83 (2000) $2409-2416$.

15 J. A. Lewis, Direct - write assembly of ceramics from colloidal inks, Curr. Opin. Solid St. M. 6 (2002) $245-250$.

${ }^{16}$ R. B. Rao, K. L. Krafcik, A. M. Morales, and J. A. Lewis, Adv. Mater. 17 (2005) 289 - 293.

${ }^{17}$ J. C. Dingeldein, K. A. Walczak, B. W. Swatowski, C. R. Friedrich, C. T. Middlebrook, and M. C. Roggemann, Process characterization for direct dispense fabrication of polymer optical multi - mode waveguides, J. Micromech. Microeng. 23 (2013) 075015 (9 pp).

${ }^{18}$ V. Tohver, S. L. Morissette, J. A. Lewis, B. A. Tuttle, J. A. Voight, and D. B. Dimos, Direct write fabrication of zinc oxide varistors, J. Am. Ceram. Soc. 85 (2002) 123 - 128.

${ }^{19}$ G. M. Gratson, F. Garcia - Santamaria, V. Lousse, M. Xu, S. Fan, J. A. Lewis, and P. V. Braun, Direct write assembly of three - dimensional photonic crystals: Conversion of polymer scaffolds to silicon hollow - woodpile structures, Adv. Mater. 18 (2006) 461 - 465.

${ }^{20}$ D. Therriault, S. R. White, and J. A. Lewis, Rheological behavior of fugitive inks for direct write assembly, Appl. Rheol. 17 (2007) 10112 (8 pp).

${ }^{21}$ B. Y. Ahn, E. B. Duoss, M. J. Motala, X. Guo, S. -I. Park, Y. Xiong, J. Youn, R. G. Nuzzo, J. A. Rogers, and J. A. Lewis, Omnidirectional printing of flexible, stretchable, and spanning silver electrodes, Science 323 (2009) 1590 - 1593.

${ }^{22}$ B. Y. Ahn, D. J. Lorang, and J. A. Lewis, Transparent conductive grids via direct writing of silver nanoparticle inks, Nanoscale 3 (2011) 2700 - 2702.

${ }^{23}$ M. A. Torres Arango, A. M. Cokeley, J. J. Beard, and K. A. Sierros, Direct writing and electromechanical characterization of Ag micro - patterns on polymer substrates for flexible electronics, Thin Solid Films 596 (2015) 167 - 173.

${ }^{24}$ J. J. Adams, E. B. Duoss, T. F. Malkowski, M. J. Motala, B. Y. Ahn, R. G. Nuzzo, J. T. Bernhard, and J. A. Lewis, Conformal printing of electrically small antennas on three dimensional surfaces, Adv. Mater. 23 (2011) 1335 - 1340.

${ }^{25}$ D. J. Lorang, D. Tanaka, C. M. Spadaccini, K. A. Rose, N. J. Cherepy, and J. A. Lewis, Photocurable liquid core - fugitive shell printing of optical waveguides, Adv. Mater. 23 (2011) $5055-5058$.

${ }^{26}$ R. Dermanaki Farahani, H. Dalir, V. Le Borgne, L. A. Gautier, M. A. El Khakani, M. Lévesque, and D. Therriault, Direct - write fabrication of free - standing nanocomposite strain sensors, Nanotechnology 23 (2012) 085502 (9 pp). 
${ }^{27}$ R. - Z. Li, A. Hu, T. Zhang, and K. D. Oakes, Direct writing on paper of foldable capacitive touch pads with silver nanowire inks, ACS Appl. Mater. Interfaces 6 (2014) 21721 - 21729.

${ }^{28}$ A. E. Jakus, E. B. Secor, A. L. Rutz, S. W. Jordan, M. C. Hersam, and N. R. Shah, Three dimensional printing of high - content graphene scaffolds for electronic and biomedical applications, ACS Nano 9 (2015) 4636 - 4638.

${ }^{29}$ E. Garcia - Tuñon, S. Barg, J. Franco, R. Bell, S. Eslava, E. D’Elia, R. C. Maher, F. Guitian, and E. Saiz, Printing in three dimensions with graphene, Adv. Mater. 27 (2015) $1688-1693$.

${ }^{30}$ K. Sun, T. -S. Wei, B. Y. Ahn, J. Y. Seo, S. J. Dillon, and J. A. Lewis, 3D printing of interdigitated Li-ion microbattery architectures, Adv. Mater. 25 (2013) 4539 - 4543.

${ }^{31}$ Y. L. Kong, I. A. Tamargo, H. Kim, B. N. Johnson, M. K. Gupta, T. -W. Koh, H. -A. Chin, D. A. Steingart, B. P. Rand, and M. C. McAlpine, 3D printed quantum dot light-emitting diodes, Nano Lett. 14 (2014) 7017 - 7023.

${ }^{32}$ M. Torres Arango, "Electro-mechanical Characterization of Directly Written Ag patterns On Plastics," ICMCTF, 2015.

${ }^{33}$ COMSOL Multiphysics, Stockholm: COMSOL AB.

${ }^{34}$ M. A. Torres Arango, A. S. Valença de Andrade, D. T. Cipollone, L. O. Grant, D. Korakakis and K. A. Sierros, "Robotic Deposition of TiO2 Films on Flexible Substrates from Hybrid Inks: Investigation of Synthesis-Processing-Microstructure-Photocatalytic Relationships," ACS Applied Materials \& Interfaces, vol. 8, pp. 24659-70, 2016.

${ }^{35}$ D. T. Mullen, M. M. Keane and R. F. D. Monaghan, "Automatic Extraction of reduced-order models from CFD simulations for building energy modelling," Elsevier, 2015.

${ }^{36}$ D. Alonso, A. Velazquez and J. M. Vega, "A method to generate computationally efficient reduced order models," Elsivier, 2009.

${ }^{37}$ Dongming Hu and Radovan Kovacevic, "Sensing, modeling and control for laser-based additive manufacturing," International Journal of Machine Tools \& Manufacture, 2002. 43:51 60 .

${ }^{38}$ Elçin Içten, Arun Giridhar, Lynne S. Taylor, Zoltan K. Nagy, Gintaras V. Reklaitis, "Dropwise Additive Manufacturing of Pharmaceutical Products for Melt-Based Dosage Forms," J Pharm Sci, 2015. 104:1641-49.

${ }^{39}$ B. A. Ogunnaike and W. H. Harmon, Process Dynamics, Modeling, and Control, New York: Oxford University Press, 1994.

${ }^{40}$ M. A. Torres Arango, A. M. Cokeley, J. J. Beard and K. A. Sierros, "Direct writing and electro-mechanical characterization of Ag micro-patterns on polymer substrates for flexible electronics," Thin Solid Films, 2015. 


\section{Appendix A}

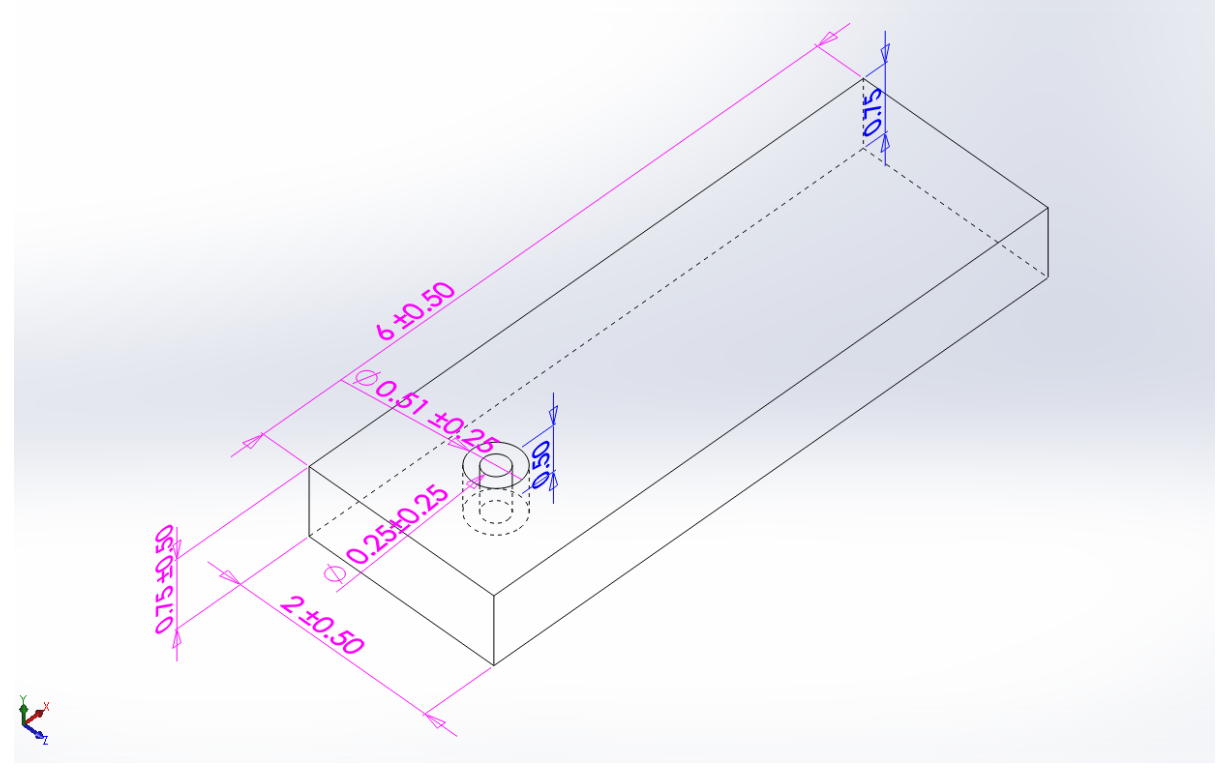

Figure 29. Dimensions of the domain for the COMSOL simulation

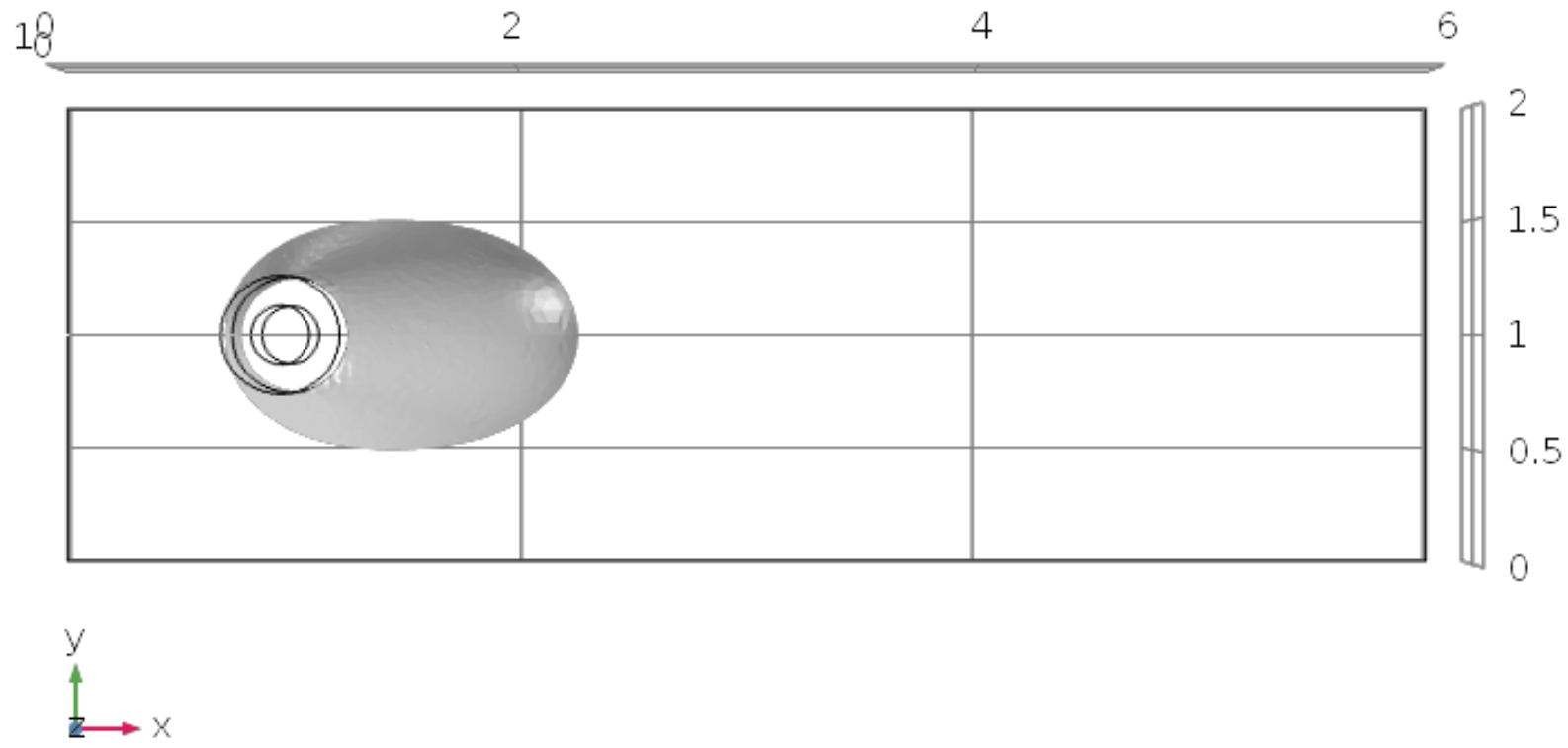

Figure 30. Deposited track at the start of the deposition. 